\title{
Aggregate Consumption-Wealth Ratio and the Cross-Section of Stock Returns: Some International Evidence ${ }^{*}$
}

\author{
Paul P.J. Gao \\ Department of Finance University of Notre Dame Notre Dame, Indiana 46556 \\ E-mail: pgao@nd.edu \\ and \\ Kevin X.D. Huang \\ Department of Economics Vanderbilt University Nashville, TN 37235 \\ E-mail: kevin.huang@vanderbilt.edu
}

\begin{abstract}
We find that the short-term deviations from long-run consumption-wealth relationship ( $\widehat{c a y})$ forecast stock market returns and serve as a conditioning variable in the capital asset pricing model (CAPM) for explaining the crosssection of stock returns for the United Kingdom and Japan. Our cross-sectional regressions using $\widehat{c a y}$ as a conditioning variable as opposed to using an alternative variable, $\widehat{t a y}$, constructed using calender time in place of consumption indicate that it is unlikely to be a spurious variable and provides useful information concerning the economic fundamentals. We show that both a consumptionbased capital asset pricing model (CCAPM) and a human-capital-augmented capital asset pricing model (HC-CAPM) in conjunction with this conditioning variable can explain much of the cross-section of stock returns in each of the two countries; yet, in terms of relative performance, our results tend to favor the conditional HC-CAPM over the conditional CCAPM for pricing U.K. and Japanese cross-sectional returns.
\end{abstract}

Key Words: Consumption-Wealth Ratio; CAPM; CCAPM; HC-CAPM; Factor Model.

JEL Classification Numbers: E21, E44, G10, G14.

* We thank Torben Andersen, Todd Clark, Kent Daniel, Ravi Jagannathan, Sydney Ludvigson, Yong Wang, and seminar participants at the Federal Reserve Bank of Kansas City for helpful discussions and comments. We are grateful to Carol Bertaut, Kent Daniel, Stefan Nagel, and many other researchers who have shared their data with us. All remaining errors are ours own.

$1529-7373 / 2008$

All rights of reproduction in any form reserved. 


\section{INTRODUCTION}

In the past two decades the Sharpe-Litner-Black capital asset pricing model (CAPM) and the consumption-based capital asset pricing model (CCAPM) have faced challenges in accounting for the cross-section of equity returns. A major anomaly appeared with the discovery of the "value effect" that stocks with lower $P / E$ ratios, lower $P / D$ ratios, or lower priceto-book values tend to have higher returns. A related anomaly arose from the finding that stocks with smaller market sizes tend to have higher returns (particularly in January). ${ }^{1}$ The (C)CAPM, despite their theoretical elegance, have had a difficult time explaining these anomalies.

On the empirical ground, Fama and French $(1992,1993)$ find that, in addition to the market return, returns on two mimicking portfolios based on size and book-to-market equity premium (e.g., the two previously identified anomalies) can help explain the cross-sectional returns of the 25 benchmark portfolios sorted on size and book-to-market ratio. Their work with Davis (Davis, Fama, and French 1996) presents similar evidence in the pre-COMPUSTAT era. They attribute these findings to the high bookto-market minus low book-to-market equity return (HML) and the small minus big return (SMB) may contain information about the risk of distress which is not captured by the (C)CAPM. Fama and French (1996) further this argument by demonstrating that many of the asset pricing anomalies discovered during the past twenty years, possibly with the exception of the "momentum effect", might be attributable to mis-specifications of the models. In a sequel, Fama and French (1998) examine a two-factor international capital asset pricing model that incorporates a global distress factor in the pricing kernel and show that it performs significantly better than a one-factor model in explaining value portfolio returns.

Recent research has devoted much effort to reconciling the theoretical soundness of the (C)CAPM and the empirical success of Fama-French multifactor models. One strand of this literature focuses on identifying additional risk factors or offering risk-based explanations of the empirical success of the Fama-French unconditional multifactor models. ${ }^{2}$ Another strand of this literature attempts to "resurrect" the (C)CAPM by identi-

\footnotetext{
${ }^{1}$ The size premium seems to have been shrinking over the last twenty years. Interested readers are referred to Basu (1977), Rosenberg, Reid and Lanstein (1985), De Bondt and Thaler (1985), Jaffe, Keim and Westerfield (1989), Chan, Hamao and Lakonishok (1991), Fama and French (1992), and Lakonishok, Shleifer and Vishny (1994) for detailed discussions of these asset pricing anomalies.

${ }^{2}$ Fama and French (1992) originally relate the B/M ratio to default or financial distress risk, while Fama and French (1995) and Chen and Zhang (1998) find indeed that firms with higher $\mathrm{B} / \mathrm{M}$ ratios tend to have lower earnings, higher financial leverage, more earning uncertainty, and are more likely to cut dividends. Jagannathan and Wang (1996) and Jagannathan, Kubota and Takehara (1998) argue that the SMB factor may proxy for risk associated with human capital or labor income. Lewis and Vassalou (2001)
} 
fying variables that contain conditioning information for time-varying risk premium or time-varying beta representation. ${ }^{3}$

The recent studies by Lettau and Ludvigson (2001a, 2001b, 2003) follow this second strand and propose aggregate consumption-wealth ratio as one such conditioning variable, as is suggested under some "mild" assumptions by a representative household's binding intertemporal budget constraints. Based on postwar U.S. data, they construct a measure of short-term deviations from a long-run cointegration relationship among the logarithm of consumption $(c)$, labor income $(y)$, and aggregate wealth $(a)$, while confirming the existence of such a cointegration relationship in their sample. Using this constructed measure, they show that such fluctuations in aggregate consumption-wealth ratio can help forecast stock market returns at short and intermediate horizons, and the measure can also serve as a useful conditioning variable in both a CCAPM and a human-capital-augmented capital asset pricing model (HC-CAPM) for explaining the cross-section of stock returns in the U.S. More specifically, the $\widehat{c a y}$ that they construct helps forecast about 9 percent of the one-quarter-ahead excess market return and explain about 70 percent of the cross-sectional returns in U.S. data within the framework of Breeden's (1979) CCAPM and Jagannathan and Wang's (1996) HC-CAPM.

This paper conducts a similar investigation for the United Kingdom and Japan. Our analysis is largely motivated by three interrelated considerations. The first and foremost is related to a general concern about "datasnooping" bias (e.g., Lo and MacKinlay 1990). Given that the data used in constructing $\widehat{c a y}$ in Lettau and Ludvigson's studies are available only at a quarterly frequency, the time series seems to be too short to allow for powerful out-of-sample tests crosstime. It is thus of particular interest to examine whether the kind of empirical success of $\widehat{c a y}$ that they report for the U.S. may also be achieved for other markets. In reality, out-of-sample tests cross-country have been a popular practice in empirical asset pricing research. ${ }^{4}$ For our analysis here, we focus on the U.K. and Japan because

establish a linkage of macroeconomic risk factors to the HML, the SMB, and the winner minus loser momentum (WML) mimicking portfolio returns.

${ }^{3}$ The emphasis on conditional asset pricing has become increasingly popular over the last twenty years. See, among many others, Wang (2004) for a brief review of this trend.

${ }^{4}$ There are many examples. As for the issue of identifying valid conditioning variables, while some more traditional candidates prove useful in predicting stock returns in the U.S., the forecasting abilities of similar variables are examined in other countries as well (even when there are sufficient time series observations in U.S. data). Among others, Harvey (1991), Ferson and Harvey (1993), and Solnik (1993) provide favorable crosscountry out-of-sample evidence for several such conditioning variables. However, there are also examples in which out-of-sample tests cross-country come up with unfavorable evidence. For instance, Griffin, Ji and Martin (2003) show that the finding by Chordia and Shivakumar (2002) that compensation for macroeconomic risk factors can explain the "momentum effect" in the U.S. may largely be country-specific. Similarly, Daniel, 
these are the next two major markets after the U.S., and because of data availability and data quality (to be discussed in more detail in Section 3). Further, this choice of our focus is broadly consistent with a general principle that Lo and MacKinlay argue should guide any out-of-sample test to minimize the likelihood of data-snooping. That is, the test should be conducted over different and weakly correlated datasets. On an a priori basis, it is known that cross-country correlation in consumption is generally weak. For example, according to Huang and Liu (2003) and the references therein, the average consumption correlation among major OECD countries is in the vicinity of 30 percent. More relevantly, the absolute value of correlation in $\widehat{c a y}$ between the U.S., the U.K., and Japan falls well within the range of 0.10-0.30 for most sub-sample periods in our data. Therefore, our empirical tests are more likely to be independent rather than correlated.

The second consideration has to do with some recent debates over the information content of $\widehat{c a y}$. For instance, Avramov (2002) and Brennan and Xia (2002) question the ability of $\widehat{c a y}$ as a conditioning variable in forecasting future stock returns. In particular, Brennan and Xia argue that the in-sample forecasting power of $\widehat{c a y}$ as reported by Lettau and Ludvigson might be spurious owing to a "look-ahead" bias introduced by the use of a full sample in estimating the cointegration parameters. They show that an alternative variable, $\widehat{t a y}$, constructed using "calender time" in place of consumption, performs at least as well as $\widehat{c a y}$ in forecasting stock returns in-sample, but neither has much out-of-sample forecasting ability based on U.S. data. The dispute has generated much controversy over the validity of using $\widehat{c a y}$ as a sensible conditioning variable in asset pricing, as manifested in the recent exchange between Brennan and Xia and Lettau and Ludvigson (2002). As the above paragraph alluded to, the kind of cross-time out-ofsample test by Brennan and Xia might have test power considerations due to the lack of sufficient quarterly time series observations. By examining the two other major markets, and by contrasting the performance of $\widehat{c a y}$ and $\widehat{t a y}$ as a conditioning variable both in forecasting future stock returns and in explaining the cross-section of stock returns, our work should help to reconcile some of the controversies.

The third consideration is born out of a recent observation by Rudd and Whelan (2002) that the measures of data employed in Lettau and Ludvigson's cointegration tests and estimations might not be jointly consistent (in either the scopes of the original nominal variables or the deflator used in defining their real counterparts) with an underlying budget constraint (on the corresponding real variables) which they use to motivate their $\widehat{c a y}$ based approach in the first place. Based on one set of budget consistent

Titman and Wei (2001) reject a risk-based explanation in favor of a characteristic-based explanation for Fama-French three-factor model based on Japanese data. 
measures, which represent some slight modifications to the ones used in the preceding analysis, Rudd and Whelan report that they cannot reject the null that there is no cointegration relation among the corresponding versions of the three real variables in postwar U.S. data. While this leaves open the question of whether there might exist a set of budget-consistent measures for U.S. data that would justify a $\widehat{c a y}$-based approach, it does raise some concerns over the validity and robustness of Lettau and Ludvigson's finding. For instance, Rudd and Whelan interpret their result as to suggesting that the "mild" assumptions behind the theoretical basis for the preceding study might not be that innocuous: the validity of a host of approximations centered around the log-linear approximation to the budget constraint that provides a starting point for the cointegration-based approach depends crucially on the assumptions as to the stability over time of a number of ratios involving some unobservable variables; or, even if those approximations are satisfactorily accurate, the existence of a cointegration relation among the three logged real variables still hinges critically on the assumptions as to the stationarity of the expected growth rate of consumption or the expected rate of return to human or asset wealth, which could fail to hold if the economy experiences periodic structural changes. ${ }^{5}$ While direct testing of these assumptions is generally difficult due to the involvement of unobservable variables, cointegration test or estimation based on a sub-sample period considerably shorter than the one used in Lettau and Ludvigson's study is likely to suffer from significant small sample biases, as noted by both Lettau and Ludvigson (2002) and Rudd and Whelan. The analysis presented in this paper uses budget consistent measures and full samples of our U.K. and Japanese data and thus should help address this issue from a different perspective. ${ }^{6}$

Our results are easy to summarize. We first construct a measure of $\widehat{c a y}$ for the United Kingdom and Japan after testing and estimating the coefficients of a cointegration relation among the three logged real variables based on the full samples of our data for the two countries. We then show that this measure constructed for the U.K. and Japan posses excellent short-term forecasting power and, more importantly, when it is used as a conditioning variable in the CCAPM or the HC-CAPM, the conditional version of either of these two models can explain the cross-section of stock returns in these two countries. Further, our cross-sectional regressions using

\footnotetext{
${ }^{5}$ The single budget representation of the infinitely many intertemporal budget constraints upon which the preceding cointegration-based approach is based also hinges on the assumption of the absence of asset pricing bubbles.

${ }^{6}$ There is a caveat in our data on Japanese asset wealth, as will be discussed in more details in Section 3. In light of this and Footnote 5, our results based on Japanese data should be interpreted with caution. The issue on data revisions and redefinitions is also discussed in Section 3.
} 
$\widehat{c a y}$ as a conditioning variable, as opposed to using an alternative variable, $\widehat{t a y}$, constructed using calender time in place of consumption, suggest that the former is unlikely to be a spurious variable in that it provides useful information concerning the economic fundamentals in the U.K. and Japan. Finally, in terms of relative performance, our empirical finding tends to favor the conditional HC-CAPM, as presented by Jagannathan and Wang (1996), over the conditional CCAPM for pricing U.K. and Japanese crosssectional returns.

The rest of the paper is organized as follows. In Section 2, we discuss briefly the theoretical footing of $\widehat{c a y}$. In Section 3, we describe in some detail our construction of the $\widehat{c a y}$ measure for the U.K. and Japan, and of the Fama-French style size and book-to-market equity double-sorted portfolio return series and factor return series, using the dynamic least square method. In Section 4, we present some preliminary statistics governing various characteristics of the testing asset, the $\widehat{c a y}$, for the two countries. We report in Section 5 our finding about the forecasting power of the $\widehat{c a y}$ at various time horizons based on our U.K. and Japanese data and in Section 6 we test the empirical performance of the conditional version of the CAPM, the CCAPM, and the HC-CAPM using the $\widehat{c a y}$ as the conditioning variable. We conclude in Section 7.

\section{THEORETICAL FOUNDATION}

The idea that aggregate consumption-wealth ratio might provide useful conditioning information for asset returns can be revealed by rewriting under some mild assumptions a representative household's binding intertemporal budget constraints into a single budget representation. The observation takes its original root in Campbell and Mankiw (1989) and is validated by Lettau and Ludvigson (2001a).

It starts with period $t$ budget constraint,

$$
W_{t+1}=\left(1+R_{W, t+1}\right)\left(W_{t}-C_{t}\right)
$$

where $W_{t}$ denotes aggregate wealth at the beginning of period $t, R_{W, t+1}$ denotes its return in period $t$, and $C_{t}$ denotes the household's consumption during period $t$, and then log-linearizes this budget equation to obtain an approximation of the log-linear consumption-wealth ratio,

$$
c_{t}-w_{t} \doteq \sum_{i=1}^{\infty} \rho_{W}^{i}\left(r_{W, t+i}-\Delta c_{t+i}\right)
$$

where the lower-case variables are the log-deviation of the corresponding level variables from their steady-state values. Here, $\Delta$ denotes the firstorder difference operator, and $\rho_{W}$ denotes the steady-state investment ratio, 
$\rho_{W}=(W-C) / W$, assuming its stability over time. Given that aggregate wealth $W_{t}$ is the sum of financial assets $A_{t}$ and human-capital $H_{t}$, the log-linear approximation of $W_{t}$ is a convex combination of the log-linear approximation of $A_{t}$ and of $H_{t}$,

$$
w_{t}=\omega a_{t}+(1-\omega) h_{t}
$$

where $\omega=A / W$, assuming its stability over time, and the return on aggregate wealth can be approximated by a weighted sum of the return on financial assets and on human capital,

$$
r_{w, t}=\omega r_{a, t}+(1-\omega) r_{h, t}
$$

If aggregate labor income well describes the nonstationary component of human capital, as suggested by several theories (see Lettau and Ludvigson 2001a for details), then a simple relation $h_{t}=\kappa+y_{t}+z_{t}$ holds, where $\kappa$ is a constant, and $z_{t}$ is a zero-mean stationary random variable.

Substituting this relation into equation (2) and taking conditional expectation, one obtains the following relationship:

$$
\begin{aligned}
& c_{t}-\omega a_{t}-(1-\omega) y_{t} \\
& =E_{t} \sum_{i=1}^{\infty} \rho_{W}^{i}\left\{\left[\omega r_{a, t+i}+(1-\omega) r_{h, t+i}\right]-\Delta c_{t+i}\right\}+(1-\omega) z_{t} .
\end{aligned}
$$

Under the assumptions that all terms on the right-hand side of equation (5) are stationary, the left-hand side must also be stationary. This implies that $c_{t}, a_{t}$ and $y_{t}$ must be cointegrated with a cointegrating vector $(1,-\omega, 1-\omega)$. Maintaining these assumptions, we will from now on denote the left-hand side of equation (5) by $\widehat{c a y}_{t}$, following Lettau and Ludvigson (2001a). The equation suggests, as they argue, that as long as expected future returns on human capital and consumption growth are not too variable, or if they are highly correlated with expected future returns on assets, $\widehat{c a y}_{t}$ should help forecast the latter. In other words, $\widehat{c a y}_{t}$ should provide useful information about market expectations of future asset returns.

\section{DATA CONSTRUCTION}

The broad purpose of this paper is to examine the empirical performance of $\widehat{c a y}$ as a conditioning variable in capital asset pricing models so as to explaining the cross-section of stock returns in the United Kingdom and Japan. Besides the justifications mentioned in the introduction, this focus on the U.K. and Japan is also motivated by the following considerations. First, for many countries, quarterly data on consumption, household 
wealth, and household incomes are not available. We have relied primarily on Bertaut (2002) but also contacted various central banks and statistical bureaus for data availability. Our investigation reveals that among major OECD countries the types of quarterly data with a satisfactory size required for our analysis are available only for Australia, Canada, France, Japan, and the U.K. Further, for some of these countries (e.g., Canada), their macro data (at the time of this project being undertaken) are undergoing substantial revisions in efforts to bridge the differences in previous publications, which make their usage rather limited. Second, besides the availability of macro data, we also need to consider the availability of equity market data. The previous literature generally uses Datastream as a primary source for these types of data. Yet, we find that Datastream (which in turn draws substantially from the WorldScope database) has very limited coverage for Australia and France in early years. As discussed in the previous literature, use of Datastream may also be subject to substantial survivorship bias, which may complicate the interpretation of the underlying results. All considered, we restrict our analysis to U.K. and Japanese data.

\subsection{Constructing $\widehat{c a y}$ and Risk-Free Rates}

Household consumption, income, and wealth data for each country are taken from the country's national income and product accounts, flow of funds accounts, and household sector balance sheet accounts. We try our best to make our data definition consistent with what has been used by Lettau and Ludvigson (2001a, b), yet some cross-country difference exists in recording and defining statistics. Our later discussions will highlight the delicacy in constructing our budget-consistent measure of $\widehat{c a y}$ for the U.K. and Japan. We proceed by first reproducing the key definitions of consumption, income, and household sector wealth from Bertaut (2002), which contains an excellent survey of the difference in definition and construction of cross-country macro variables.

The total personal consumption expenditures taken from each country's national income and product accounts are used in constructing aggregate consumption for each country. To construct aggregate income, total personal disposable income is used for the United Kingdom and the compensation of employees is used for Japan. To construct aggregate wealth, we take somewhat different approaches for the U.K. than for Japan, depending on data availability. For the U.K., we use the quarterly total household sector wealth, consistent with the wealth measure used by Lettau and Ludvigson (2001) for the U.S. For Japan, quarterly household sector wealth data are not available, and we instead use the financial sector household wealth as 
a proxy, following Bertaut (2002). ${ }^{7}$ To construct the risk-free rates, we use the 91-day government bond yield (RMGBS@UK) from the Global Insights for the U.K., and the 30-day Gensaki rate from PACAP database for Japan, as in Daniel et al. (2001).

After constructing the consumption, income, and wealth data, we test and estimate cointegration relations among the three variables. We first examine whether there exists a cointegration relationship among (the logarithm of) consumption, real income, and aggregate household wealth, defined and constructed above for the U.K. and Japan. For this purpose, we conduct the Phillips-Ouliaris (1990) residual based test, as well as the Johansen $(1988,1991)$ likelihood based rank and trace tests. The number of lead and lag terms included in the specifications are determined by the information criteria (AIC and BIC) and the degree of significance of the lead and lag terms used in the dynamic least-square (DLS) regression. The Dickey-Fuller statistics are applied to the residuals of the DLS to test the null hypothesis of a unit root in the residuals that would imply the absence of a cointegration relationship among the variable under consideration. The number of lags in the Dickey-Fuller regression is chosen based on the AIC and SBC information criteria. Lags here refer to the number of lags of first order differences used in the regression in obtaining the Dickey-Fuller test statistics. Our testing results generally support the hypothesis that a stable cointegrating relation among the three variables exists for the U.K. and Japan once the number of lags is appropriately chosen. These testing results are summarized in Table 1.

TABLE 1.

Philips-Ouliaris Test and Johansen Test for Cointegration Relationship among Log-consumption, Log-income, and Log-household wealth

Panel A: Philips-Olarius Cointegration Test Statistics for the United Kingdom (1970:Q1 - 2000:Q3)

\begin{tabular}{|l|c|c|c|c|c|c|c|}
\hline & $\mathrm{Lag}=1$ & $\mathrm{Lag}=2$ & $\mathrm{Lag}=3$ & $\mathrm{Lag}=4$ & \multicolumn{2}{c|}{ Critical Values at 1-, 5- and 10\% level } \\
\hline Dickey-Fuller test statistic & -9.93 & -7.47 & -6.96 & -6.24 & $1 \%$ Critical Level & $5 \%$ Critical Level & 10\% Critical Level \\
\hline Akaike information criterion & -5.87 & -5.85 & -5.85 & -5.83 & -4.36 & -3.80 & -3.52 \\
\hline Schwarz criterion & -5.80 & -5.76 & -5.73 & -5.69 & & & \\
\hline
\end{tabular}

To estimate the cointegration relationship, we follow Lettau and Ludvigson $(2002 a, b)$ and use the DLS method developed by Watson (1993). In

\footnotetext{
${ }^{7}$ If households hold well diversified portfolios and their financial wealth is proportional to the total household sector wealth, then the cointegration vector will capture the longrun relationship.
} 
Panel B: Johansen's Cointegration Test Statistics (Maximum Eigenvalue and Trace Statistics) for the United Kingdom

\begin{tabular}{|c|c|c|c|c|c|c|c|c|}
\hline \multicolumn{5}{|c|}{ L-max Statistics } & \multicolumn{4}{|c|}{ Trace Statistics } \\
\hline $\begin{array}{l}\text { Hypothesized } \\
\text { Number of } \\
\text { Cointegration } \\
\text { Equations }\end{array}$ & $\begin{array}{c}\text { Max-Eigenvalue } \\
\text { Statistic }\end{array}$ & $\begin{array}{c}10 \% \\
\text { Critical } \\
\text { Value }\end{array}$ & $\begin{array}{c}5 \% \\
\text { Critical } \\
\text { Value }\end{array}$ & $\begin{array}{c}1 \% \\
\text { Critical } \\
\text { Value }\end{array}$ & $\begin{array}{c}\text { Trace } \\
\text { Statistic }\end{array}$ & $\begin{array}{c}10 \% \\
\text { Critical } \\
\text { Value }\end{array}$ & $\begin{array}{c}5 \% \\
\text { Critical } \\
\text { Value }\end{array}$ & $\begin{array}{c}1 \% \\
\text { Critical } \\
\text { Value }\end{array}$ \\
\hline \multicolumn{9}{|c|}{ Lags in VAR Model $=1$} \\
\hline None & 13.42 & 13.39 & 20.97 & 25.52 & 24.45 & 26.70 & 29.68 & 35.65 \\
\hline At most 1 & 10.44 & 10.6 & 14.07 & 18.63 & 11.03 & 13.31 & 15.41 & 20.04 \\
\hline At most 2 & 0.59 & 2.71 & 3.76 & 6.65 & 0.59 & 2.71 & 3.76 & 6.65 \\
\hline \multicolumn{9}{|c|}{ Lags in VAR Model $=2$} \\
\hline None & 11.78 & 13.39 & 20.97 & 25.52 & 19.22 & 26.70 & 29.68 & 35.65 \\
\hline At most 1 & 7.064 & 10.6 & 14.07 & 18.63 & 7.44 & 13.31 & 15.41 & 20.04 \\
\hline At most 2 & 0.37 & 2.71 & 3.76 & 6.65 & 0.37 & 2.71 & 3.76 & 6.65 \\
\hline \multicolumn{9}{|c|}{ Lags in VAR Model $=3$} \\
\hline None & 13.82 & 13.39 & 20.97 & 25.52 & 20.73 & 26.70 & 29.68 & 35.65 \\
\hline At most 1 & 6.90 & 10.6 & 14.07 & 18.63 & 6.91 & 13.31 & 15.41 & 20.04 \\
\hline At most 2 & 0.02 & 2.71 & 3.76 & 6.65 & 0.02 & 2.71 & 3.76 & 6.65 \\
\hline \multicolumn{9}{|c|}{ Lags in VAR Model $=4$} \\
\hline None & 18.17 & 13.39 & 20.97 & 25.52 & 25.52 & 26.70 & 29.68 & 35.65 \\
\hline At most 1 & 7.35 & 10.6 & 14.07 & 18.63 & 7.35 & 13.31 & 15.41 & 20.04 \\
\hline At most 2 & 0.00 & 2.71 & 3.76 & 6.65 & 0.00 & 2.71 & 3.76 & 6.65 \\
\hline
\end{tabular}

Panel C: Philips-Olarius Cointegration Test Statistics for Japan (1981:Q4-2001:Q1)

\begin{tabular}{|l|c|c|c|c|c|c|c|}
\hline & $\mathrm{Lag}=1$ & $\mathrm{Lag}=2$ & $\mathrm{Lag}=3$ & $\mathrm{Lag}=4$ & \multicolumn{2}{|c|}{ Critical Values at 1-, 5- and 10\% level } \\
\hline Dickey-Fuller test statistic & -7.69 & -6.56 & -4.50 & -3.58 & $1 \%$ Critical Level & $5 \%$ Critical Level & 10\% Critical Level \\
\hline Akaike information criterion & -5.79 & -5.77 & -5.75 & -5.73 & -4.36 & -3.80 & -3.52 \\
\hline Schwarz criterion & -5.70 & -5.65 & -5.60 & -5.55 & & & \\
\hline
\end{tabular}

particular, we estimate the following equation:

$$
c_{t}=\alpha+\beta_{a} a_{t}+\beta_{y} y_{t}+\sum_{i=-k}^{i=k} b_{a, i} \Delta a_{t-i}+\sum_{i=-k}^{i=k} b_{y, i} \Delta y_{t-i}+\varepsilon_{t}
$$

where $\Delta$ denotes the first difference operator, and $k$ is chosen to truncate the series according to the information criteria. ${ }^{8}$ Our estimation results are summarized in Table 2 .

\footnotetext{
${ }^{8}$ As a robustness check, we experiment over different numbers of lead and lag terms in the DLS. We find that our results are not sensitive in that the magnitude and statistical significance of the regression coefficients are almost invariant to the different specifications.
} 
Panel D: Johansen's Cointegration Test Statistics (Maximum Eigenvalue and Trace Statistics) for Japan

\begin{tabular}{|c|c|c|c|c|c|c|c|c|}
\hline \multicolumn{5}{|c|}{ L-max Statistics } & \multicolumn{4}{|c|}{ Trace Statistics } \\
\hline $\begin{array}{l}\text { Hypothesized } \\
\text { Number of } \\
\text { Cointegration } \\
\text { Equations }\end{array}$ & $\begin{array}{c}\text { Max-Eigenvalue } \\
\text { Statistic }\end{array}$ & $\begin{array}{c}10 \% \\
\text { Critical } \\
\text { Valu }\end{array}$ & $\begin{array}{c}5 \% \\
\text { Critical } \\
\text { Value }\end{array}$ & $\begin{array}{c}1 \% \\
\text { Critical } \\
\text { Value }\end{array}$ & $\begin{array}{c}\text { Trace } \\
\text { Statistic }\end{array}$ & $\begin{array}{c}10 \% \\
\text { Critical } \\
\text { Value }\end{array}$ & $\begin{array}{c}5 \% \\
\text { Critical } \\
\text { Value }\end{array}$ & $\begin{array}{c}1 \% \\
\text { Critical } \\
\text { Value }\end{array}$ \\
\hline \multicolumn{9}{|c|}{ Lags in VAR Model $=1$} \\
\hline None & 37.15 & 13.39 & 20.97 & 25.52 & 69.27 & 26.70 & 29.68 & 35.65 \\
\hline At most 1 & 26.79 & 10.6 & 14.07 & 18.63 & 32.13 & 13.31 & 15.41 & 20.04 \\
\hline At most 2 & 5.33 & 2.71 & 3.76 & 6.65 & 5.33 & 2.71 & 3.76 & 6.65 \\
\hline \multicolumn{9}{|c|}{ Lags in VAR Model $=2$} \\
\hline None & 55.67 & 13.39 & 20.97 & 25.52 & 33.18 & 26.70 & 29.68 & 35.65 \\
\hline At most 1 & 22.49 & 10.6 & 14.07 & 18.63 & 16.76 & 13.31 & 15.41 & 20.04 \\
\hline At most 2 & 5.73 & 2.71 & 3.76 & 6.65 & 5.73 & 2.71 & 3.76 & 6.65 \\
\hline \multicolumn{9}{|c|}{ Lags in VAR Model $=3$} \\
\hline None & 25.58 & 13.39 & 20.97 & 25.52 & 52.21 & 26.70 & 29.68 & 35.65 \\
\hline At most 1 & 19.49 & 10.6 & 14.07 & 18.63 & 26.63 & 13.31 & 15.41 & 20.04 \\
\hline At most 2 & 7.14 & 2.71 & 3.76 & 6.65 & 7.14 & 2.71 & 3.76 & 6.65 \\
\hline \multicolumn{9}{|c|}{ Lags in VAR Model $=4$} \\
\hline None & 22.95 & 13.39 & 20.97 & 25.52 & 48.43 & 26.70 & 29.68 & 35.65 \\
\hline At most 1 & 20.37 & 10.6 & 14.07 & 18.63 & 25.48 & 13.31 & 15.41 & 20.04 \\
\hline At most 2 & 5.11 & 2.71 & 3.76 & 6.65 & 5.11 & 2.71 & 3.76 & 6.65 \\
\hline
\end{tabular}

Panel A and C report the results of Philips-Ouliaris residual based cointegration test for the United Kingdom and Japan. The dynamic Least-Square (DLS) method obtains the cointegrating vector among the logarithm of consumption, income, and wealth, while residuals from the cointegration relationship are consequently obtained. The number of lead and lag terms are obtained from two information criteria, AIC and BIC, as well as the significance of the lead and lag terms used in the regression analysis. The Dickey-Fuller statistics are applied to the residuals to test the null hypothesis that there is a unit root in the residuals, which in turn implies that there is no cointegration relationship among the variable under consideration. The number of lags is chosen according to the Schwarz-Bayesian criterion, and the corresponding $\mathrm{AIC}$ and SBC values are reported in the table. Lags here refer to the number of lags of first-order differences used in the regression in obtaining the Dickey-Fuller test statistics. The significance of the Philips-Ouliaris test statistics are obtained from Table B.9, Case 3 in Hamilton (1994), which in turn draws the simulation results from Philips and Ouliaris (1990). Panels B and D show the results of Johansen's cointegration test with linear trend in the data, where both maximum eigenvalue statistics and trace statistics are reported.

These empirical estimation results are broadly consistent with those obtained by Bertaut (2002). For the U.K. sample, we establish similarly a stable and theory consistent cointegration relationship between the three variables for the period of 1970:Q3 to 2000:Q3. As in Bertaut, our investigation points to possible parameter instability across the whole sample for Japan; but, after we restrict attention to the sample period of 1980:Q1 to 2001:Q3, we establish a stable and theory consistent cointegration relation among the three variables under consideration. 
TABLE 2.

Estimation of Aggregate Consumption, Income, and Wealth Ratio (CAY) Using the Dynamic Least Square (DSL) Method

Panel A: Dynamic Least-Square (DLS) Estimation of Cointegration Relationship among Aggregate Consumption, Income, and Wealth for the United Kingdom

\begin{tabular}{|c|c|c|c|}
\hline Variable & Coefficient & Std. Error & $t$-Statistic \\
\hline Log (Real Income) & 0.63 & 0.04 & 15.72 \\
\hline & & 0.02 & 25.22 \\
\hline Log (Real Household Net worth) & 0.19 & 0.02 & 8.34 \\
\hline & & 0.01 & 13.66 \\
\hline
\end{tabular}

Panel B: Dynamic Least-Square (DLS) Estimation of Cointegration Relationship among Aggregate Consumption, Income, and Wealth for Japan

\begin{tabular}{|c|c|c|c|}
\hline Variable & Coefficient & Std. Error & $t$-Statistic \\
\hline Log (Real Income) & 0.79 & 0.12 & 6.5531 \\
\hline & & 0.08 & 10.2344 \\
\hline Log (Real Household Net worth) & 0.31 & 0.06 & 5.6382 \\
\hline & & 0.04 & 8.9119 \\
\hline
\end{tabular}

Panel A describes the estimation of cointegration coefficients for aggregate consumption, income, and wealth applying Watson's (1993) dynamic least-square method to U.K. data spanning from 1970:Q3 to 2000:Q3. We ignore the lead and lag terms of logarithm of real income and logarithm of real household wealth in the table, and only report the coefficients for the contemporaneous terms. The top rows report the value of the Newey-West HAC standard errors and t-statistics, and the bottom rows show the White standard errors and t-statistics. The number of lags used in the dynamic least-square estimation is chosen such that either the lags significant at $5 \%$ level are kept, or the model specification coincides with the proposed model according to SBC information criterion. For the United Kingdom, we choose the number of lead and lag terms to be one. Panel B describes the same procedure applied to Japanese data spanning from 1980:Q1 to 2001:Q1. We choose the number of lead and lag terms to be two. For the definition of variables used in the regression, please refer to the previous table. After subtracting the mean, the estimated CAY for the United Kingdom is cay $(t)=$ $\log$ (real consumption $)-0.63 \log$ (real income $)-0.19 \log$ (real household net worth), and the estimated CAY for Japan is cay $(t)=\log$ (real consumption $)-0.79 \log$ (real income) $0.31 \log$ (real household net worth).

Panel A in the table reports the estimated cointegration coefficients for the U.K. Note that we report only the coefficients for the contemporaneous terms. The top rows report the values of the Newey-West HAC standard errors and $t$-statistics, and the bottom rows show the White standard errors and t-statistics. The number of lags used in the dynamic least-square estimation is chosen such that either the lags significant at the 5 percent level are kept, or the model specification coincides with the proposed model according to SBC information criterion. This leads to the choice of the number of lead and lag terms to be one. Panel B in the table describes the 
same procedure applied to Japanese data. In both the U.K. and Japan, the time series regression coefficients are highly significant, as shown by very high t-statistics constructed based on White (1982) and Newey and West (1987) robust variance-covariance estimator. Further, the least-square estimates of the cointegrating vector parameter values are "superconsistent", and no adjustment in the corresponding $t$-statistics is needed for the regression coefficients estimated here and the econometric tests to be carried out later

For the United Kingdom, the aggregate consumption-wealth ratio is estimated as

$$
\begin{aligned}
\widehat{c a y}_{t}^{U K}= & \log (\text { real consumption })-0.63 \log (\text { real income }) \\
& -0.19 \log (\text { real household net worth }),
\end{aligned}
$$

and for Japan, it is given by

$$
\begin{aligned}
\widehat{c a y}_{t}^{J P}= & \log (\text { real consumption })-0.78 \log (\text { real income }) \\
& -0.31 \log (\text { real household net worth }) .
\end{aligned}
$$

Consistent with the literature, when using $\widehat{c a y}$ as a conditioning variable in our cross-sectional asset pricing tests below, we will apply its demeaned values.

\subsection{Constructing the Fama-French Portfolio Returns and Fac- tor Returns}

For the United Kingdom, we use a modified version of the Fama-French portfolio returns and factor returns originally constructed by Dimson, Nagel, and Quigley (2003). This database has one important advantage over those used in the previous studies in that it is "survivorship bias" free, since, much in the way Davis, Fama, and French (1994) construct the U.S. version of the Fama-French portfolio returns and factor returns, a substantial amount of accounting information was hand-collected from the London Stock Exchange Yearbook. Yet, instead of having 25 portfolios as in the U.S. version, it contains only 16 portfolios. This is primarily due to the fact that in the U.K. size is correlated with book-to-market equity more strongly than in the U.S., and thus going to 25 portfolios would result in too few stocks in two of the corner portfolios, that is, the small and low book-to-market equity firms, and the big and high book-to-market equity firms. Further, the breakpoints are set at 40-60-80 for size and 25-50-75 percentiles for book to market ratio.

For Japan, we generally extend the dataset used by Daniel, Titman, and Wei (2001), which ends in December 1997, to the later years obtained from 
PACAP database, though some anomalous facts emerging from the data construction procedure after 1997, which are possibly associated with the East Asian financial crises late 90's, are worth mentioning here.

If we conduct an independent sort of all firms in the sample based on the market capital (size) and book-to-market equity, there is no firm inside the big and high book-to-market equity portfolio in the year 1998. For the years 1999 to 2001, there are a few firms inside that particular portfolio. Meanwhile, there is also a substantial drop in the number of firms in the small and low book-to-market equity firm portfolio. We are thus left with several choices. First, we can conduct a non-independent sort based on the size and book-to-market equity, as in Lewis and Vassalou (2001). Yet, as noted in Daniel et al., this would result in much less crosssectional variation of returns. Second, we can conduct a non-independent sort only for the year of 1998. We find that this "hybrid" procedure generates quite different sample characteristics. Therefore, independent and dependent sorts do not substitute with each other. To ensure consistency in measures of cross-sectional variation of returns, it seems that best to drop this particular year from our Japanese sample. Furthermore, since the sample characteristics are different since 1997, as a robust check, we implement the asset pricing tests for both the whole sample and for the sample containing only the data before 1997. Finally, we do not create the series by a non-independent sort because it would narrow the dispersion of value premium and make it difficult to compare our results with those obtained in the previous literature.

\section{PRELIMINARY STATISTICS OF FACTORS AND TESTING ASSETS}

We proceed by first reporting some preliminary statistics of factors and testing assets based on the Fama-French size and book-to-market equity double-sorted portfolio returns and factor returns. We find a substantial value premium in U.K. data, which is consistent with findings in the existing literature, with the highest value premium (fixing the size) of 2.06 percent per quarter. In contrast, there is no value or size premium in Japanese data, with the highest growth premium (or negative value premium) of 2.43 percent per quarter. Panel B of Table 3 indicates that growth (large) stocks outperform value (small) stocks in Japan, which is the opposite of the U.K. data. In general, the volatility of the Fama-French portfolio returns as measured by the standard deviation of returns is greater in Japan than in the U.K. data.

We now provide some descriptive statistics of factors and scaled factors. The descriptive statistics for the sample characteristics of factors used in the multi-factor asset pricing models are presented in Table 4. 
TABLE 3.

Descriptive Statistics for Fama-French Size and Book to Market Ratio Double Sorted Portfolio Returns

Panel A: Mean and Standard Deviation of Average Quarterly (4X4) Fama-French Portfolio Returns (1971-2001) in the U.K.

\begin{tabular}{|c|c|c|c|c|c|c|c|c|c|c|}
\hline \multicolumn{11}{|c|}{ Size } \\
\hline & & Small & 2 & 3 & Big & & Small & 2 & 3 & Big \\
\hline & \multicolumn{5}{|c|}{ Average Quarterly Portfolio Returns (1971-2001) } & \multicolumn{5}{|c|}{ Average Standard Deviation of Quarterly Returns (1971-2001) } \\
\hline \multirow{4}{*}{$\begin{array}{c}\text { BV/MV } \\
\text { Ratio }\end{array}$} & Low 1 & 0.0432 & 0.0399 & 0.0414 & 0.0405 & 0.1429 & 0.1223 & 0.1282 & 0.1282 & 0.1213 \\
\hline & 2 & 0.0499 & 0.0501 & 0.0453 & 0.0405 & 0.1155 & 0.1185 & 0.1194 & 0.1194 & 0.1074 \\
\hline & 3 & 0.0543 & 0.0528 & 0.0538 & 0.0475 & 0.1157 & 0.1159 & 0.1295 & 0.1295 & 0.1147 \\
\hline & High 4 & 0.0625 & 0.0567 & 0.0620 & 0.0473 & 0.1103 & 0.1203 & 0.1382 & 0.1382 & 0.1228 \\
\hline
\end{tabular}

Panel B: Mean and Standard Deviation of (5X5) Average Quarterly Fama-French Portfolio Returns (1980-2001) in Japan

\begin{tabular}{|c|c|c|c|c|c|c|c|c|c|c|c|}
\hline \multicolumn{12}{|c|}{ Size } \\
\hline & & Small 1 & 2 & 3 & 4 & Big 5 & Small 1 & 2 & 3 & 4 & Big 5 \\
\hline & \multicolumn{6}{|c|}{ Average Quarterly Return (1980-2001) } & \multicolumn{5}{|c|}{ Average Standard Deviation of Quarterly Return (1980-2001) } \\
\hline \multirow{3}{*}{$\mathrm{BV} / \mathrm{MV}$} & Low 1 & 0.0348 & 0.0324 & 0.0401 & 0.0309 & 0.0319 & 0.1817 & 0.1578 & 0.1496 & 0.1409 & 0.1398 \\
\hline & 2 & 0.0139 & 0.0185 & 0.0285 & 0.0211 & 0.0297 & 0.1564 & 0.1413 & 0.1402 & 0.1280 & 0.1287 \\
\hline & 3 & 0.0075 & 0.0167 & 0.0174 & 0.0192 & 0.0268 & 0.1470 & 0.1401 & 0.1266 & 0.1251 & 0.1321 \\
\hline \multirow[t]{2}{*}{ Ratio } & 4 & 0.0071 & 0.0114 & 0.0151 & 0.0213 & 0.0193 & 0.1404 & 0.1255 & 0.1267 & 0.1218 & 0.1294 \\
\hline & High 5 & 0.0105 & 0.0172 & 0.0234 & 0.0338 & 0.0193 & 0.1528 & 0.1303 & 0.1301 & 0.1239 & 0.1278 \\
\hline
\end{tabular}

For the U.K., while the consumption growth rate $(D R C O N)$ scaled by the beginning of period consumption-wealth ratio $\widehat{c a y}_{t-1}$, denoted as $D R C O N \times C A Y$, and quarterly excess market return, $M E R Q$, are not statistically different from zero, all of the other factors or factors scaled by $\widehat{c a y}_{t}$ are significantly different from zero at the 1 percent significance level. The beginning of period consumption-wealth ratio shows mild correlation with the current period consumption grow rate as of -14 percent, with excess market return as of 0.20 , with the risk-free interest rate as of -0.21 , and weak correlation with the high book-to-market equity minus low bookto-market equity portfolio quarterly returns $H M L Q$ equal to -0.01 and with the small minus big quarterly return $S M B Q$ equal to 0.02. For Japan, the correlation between the beginning of period consumption-wealth ratio and quarterly excess market return is weaker than that in the U.K., but both the sign and magnitude of correlation coefficients are the same. In contrast, the correlation coefficients between $\widehat{c a y}_{t-1}$ and $H M L Q$ and between $\widehat{c a y}_{t-1}$ and SMBQ in Japan are reversed in sign as compared to the case with the U.K., equal to 0.05 and -.07 , respectively. 
TABLE 4.

Descriptive Statistics of Components of Linear Pricing Kernel

Panel A: Descriptive Statistics and Correlation of Regressors for the United Kingdom

\begin{tabular}{|l|c|c|c|c|c|c|c|c|c|c|}
\hline & CAY $(\mathrm{UK})$ & DRCON & DRCON*CAY & DRINC & DRINC*CAY & HMLQ & MERQ*CAY & MERQ & RFQ & SMBQ \\
\hline Mean & 0.0000 & 0.0069 & 0.0000 & 0.0069 & 0.0001 & 0.0041 & 0.0001 & 0.0055 & 0.0073 & 0.0007 \\
\hline Median & -0.0008 & 0.0073 & 0.0000 & 0.0068 & 0.0000 & 0.0037 & 0.0000 & 0.0089 & 0.0074 & 0.0023 \\
\hline Maximum & 0.0368 & 0.0546 & 0.0005 & 0.0662 & 0.0012 & 0.0531 & 0.0063 & 0.1960 & 0.0125 & 0.0533 \\
\hline Minimum & -0.0335 & -0.0384 & -0.0014 & -0.0356 & -0.0008 & -0.0735 & -0.0019 & -0.1047 & 0.0035 & -0.0861 \\
\hline Std. Dev. & 0.0165 & 0.0116 & 0.0002 & 0.0171 & 0.0003 & 0.0164 & 0.0007 & 0.0349 & 0.0024 & 0.0215 \\
\hline T-value & & 6.60 & -1.23 & 4.50 & 2.44 & 2.79 & 1.75 & 1.75 & 34.26 & 0.37 \\
\hline & CAY(UK) & DRCON & DRCON*CAY & DRINC & DRINC*CAY & HMLQ & MERQ*CAY & MERQ & RFQ & SMBQ \\
\hline CAY(UK) & 1 & & & & & & & & & \\
\hline DRCON & -0.1411 & 1 & & & & & & & & \\
\hline DRCON*CAY & 0.2752 & 0.0517 & 1 & & & & & & & \\
\hline DRINC & 0.2347 & 0.3442 & 0.1137 & 1 & & & & & & \\
\hline DRINC*CAY & 0.3230 & -0.0497 & 0.3959 & 0.1228 & 1 & & & & & \\
\hline HMLQ & -0.0149 & 0.0377 & -0.0967 & -0.0125 & -0.0652 & 1 & & & & \\
\hline MERQ*CAY & 0.2289 & -0.2045 & -0.0393 & -0.0707 & 0.0760 & -0.1106 & 1 & & & \\
\hline MERQ & 0.2033 & -0.0544 & -0.0946 & -0.0055 & -0.0428 & -0.1478 & 0.4334 & 1 & & \\
\hline RFQ & -0.2059 & -0.2889 & -0.2245 & -0.1645 & -0.0814 & -0.0772 & 0.0257 & -0.0892 & 1 & \\
\hline SMBQ & 0.0196 & 0.2695 & 0.0798 & 0.1158 & 0.1353 & 0.0050 & -0.2844 & -0.2089 & -0.2723 & 1 \\
\hline
\end{tabular}

\section{THE PREDICTIVE POWER OF $\widehat{C A Y}$}

To get a quantitative feel for the forecasting power of $\widehat{c a y}$, we conduct an informal test using ordinary least-square regressions based on a full sample. Panel A in Table $\mathrm{V}$ reports the results from running the following OLS regression:

$$
R_{m}(t+k)-R_{f}(t+k)=a_{0}+a_{1} \widehat{c a y}_{t}+e_{t},
$$

including the unadjusted and adjusted $R^{2}$, regression coefficients, and NeweyWest HAC t-statistics. In the above regression, $R_{m}(t+k)$ is the market portfolio return $k$ period ahead and $R_{f}(t+k)$ is the risk-free interest rate (on local market) $k$ period ahead. As indicated by the Durbin-Watson statistics, serial correlation may not be an issue of concern in our regression analysis. For the U.K., $\widehat{c a y}$ contain a substantial amount of information about the upcoming quarters, as revealed by the relatively high $R^{2}$ (5 percent approximately) and the significance of it as a regressor. The predictive power of $\widehat{c a y}$, as reflected in the forecasting regression of the four quarter ahead excess market return on it, decreases as the forecasting horizon gets longer (1 percent and 0 percent respectively). For Japan, $\widehat{c a y}$ 
Panel B: Descriptive Statistics and Correlation of Regressors for Japan

\begin{tabular}{|l|c|c|c|c|c|c|c|c|c|c|}
\hline & CAY(JP) & DRCON & DRCON*CAY & DRINC & DRINC*CAY & HMLQ & MERQ & MERQ*CAY & RFQ & SMBQ \\
\hline Mean & 0.0000 & 0.0096 & 0.0000 & 0.0065 & 0.0000 & 0.0156 & 0.0076 & 0.0003 & 0.0106 & 0.0105 \\
\hline Median & 0.0043 & 0.0112 & 0.0000 & 0.0060 & 0.0000 & 0.0098 & 0.0271 & 0.0000 & 0.0103 & 0.0145 \\
\hline Maximum & 0.0401 & 0.0296 & 0.0005 & 0.1055 & 0.0009 & 0.2788 & 0.2214 & 0.0199 & 0.0286 & 0.4367 \\
\hline Minimum & -0.0685 & -0.0341 & -0.0019 & -0.0858 & -0.0012 & -0.2021 & -0.3342 & -0.0049 & 0.0006 & -0.2447 \\
\hline Std. Dev. & 0.0210 & 0.0103 & 0.0003 & 0.0192 & 0.0003 & 0.0683 & 0.0986 & 0.0027 & 0.0068 & 0.0927 \\
\hline Observations & 84 & 84 & 84 & 84 & 84 & 84 & 84 & 84 & 84 & 84 \\
\hline$t$-statistics & & 8.52 & -0.73 & 3.10 & 1.58 & 2.09 & 0.70 & 0.88 & 14.19 & 1.04 \\
\hline & CAY(JP) & DRCON & DRCON*CAY & DRINC & DRINC*CAY & HMLQ & MERQ & MERQ CAY & RFQ & SMBQ \\
\hline CAY(JP) & 1 & & & & & & & & & \\
\hline DRCON & -0.1392 & 1 & & & & & & & & \\
\hline DRCON*CAY & 0.6922 & -0.2490 & 1 & & & & & & & \\
\hline DRINC & 0.1145 & 0.4319 & -0.0045 & 1 & & & & & & \\
\hline DRINC*CAY & 0.5036 & -0.2294 & 0.6022 & -0.0008 & 1 & & & & & \\
\hline HMLQ & 0.0419 & 0.1472 & -0.0320 & 0.2120 & 0.0220 & 1 & & & & \\
\hline MERQ & 0.1266 & 0.0315 & 0.0668 & -0.1983 & 0.1792 & -0.0165 & 1 & & & \\
\hline MERQ ${ }^{*}$ CAY & -0.2090 & -0.0230 & 0.0550 & 0.0688 & -0.1165 & 0.0960 & -0.1699 & & 1 & \\
\hline RFQ & -0.1471 & 0.4206 & -0.1735 & 0.1100 & -0.0374 & 0.1656 & -0.0150 & 0.1092 & 1 & \\
\hline SMBQ & -0.0685 & 0.0949 & -0.1221 & 0.1015 & -0.2241 & 0.3305 & 0.1610 & 0.1506 & 0.0348 & 1 \\
\hline
\end{tabular}

seems to contain somewhat less information about the first quarter looking forward, but its information content seems to increase substantively as the forecast horizon increases to four quarters, and then to decrease as the forecast horizon extends to sixteen quarters ahead ( 5 percent and 0 percent respectively). See Table $\mathrm{V}$ for the details.

Figures 1 and 2 illustrate the forecasting power of $\widehat{c a y}$. The two figures plot respectively the quarterly excess market return, $E M R Q_{t+1}$, the HML portfolio return $H M L Q_{t+1}$, and the SMB portfolio return, $S M B Q_{t+1}$, against the beginning of period $\widehat{c a y}$ for the U.K. and Japan. These figures illustrate a striking pattern in which $\widehat{c a y}$ predicts excess market return $E M R Q_{t+1}$ : the "directional" forecasting of excess market return $E M R Q_{t+1}$ by $\widehat{c a y}_{t}$ is strong in that it seems to capture market movements most of the time. We formally test the observation using a rank-and-sign based test which confirms our visual observation. However, $\widehat{c a y}$ does not seem to help much in forecasting the HMLQ and SMBQ portfolio returns, as revealed by the low $R^{2}$ and insignificant regression t-statistics.

As a custom, we also examine the power of $\widehat{c a y}$ in forecasting accumulative excess returns. Panel B in Table VI reports the results from running the following ordinary least-square regression, with the cumulative excess market return over the next $K$ quarters being the dependent variable on 
FIG. 1. Quarterly excess market return and mimicking portfolio returns versus one-quarter lagged CAY in the United Kingdom from 1970:Q1 to 2001:Q1.

FIG. 1a. Excess market return (solid line) versus CAY (broken line).

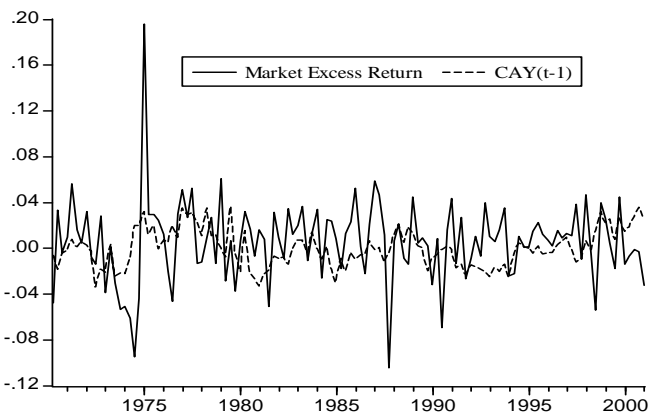

FIG. 1b. High B/M minus low B/M portfolio return (solid line) versus CAY (broken line).

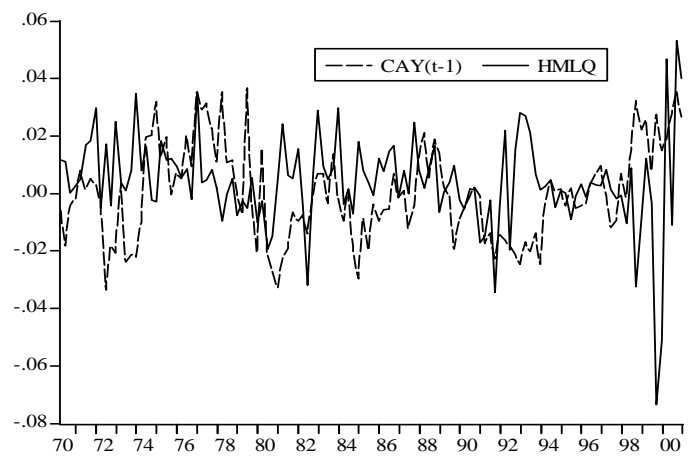

FIG. 1c. Large-size minus small-size portfolio return (solid line) versus CAY (broken line).

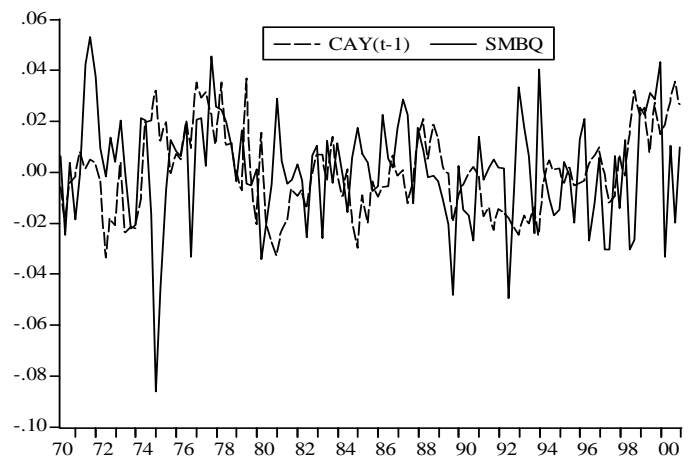


TABLE 5.

Time-Series Predictability of Excess Market Return by CAY Panel A: 1-, 4- and 16- Quarter-Ahead Excess Market Return Forecast

\begin{tabular}{|l|c|c|c|c|c|c|c|}
\hline & \multicolumn{2}{|c|}{1 Quarter Ahead } & \multicolumn{3}{c|}{ 4 Quarter Ahead } \\
\hline Variable & $a_{0}$ & $a_{1}$ & $R^{2}$ & $a_{0}$ & $a_{1}$ & $R^{2}$ \\
\hline \multicolumn{8}{|c|}{ The United Kingdom } \\
\hline Estimate & 0.02 & 1.43 & 0.05 & 0.02 & 0.81 & 0.01 \\
$t$-values & 2.21 & 2.13 & 0.04 & 2.37 & 1.55 & 0.00 \\
\hline \multicolumn{8}{|c|}{ Japan } \\
\hline Estimate & 0.01 & 0.59 & 0.02 & 0.01 & 1.02 & 0.05 \\
t-values & 0.68 & 1.13 & 0.00 & 0.54 & 1.74 & 0.03 \\
\hline
\end{tabular}

Panel B: 1-, 4- and 16- Quarter-Ahead Accumulative Excess Market Return Forecast

\begin{tabular}{|l|c|c|c|c|c|c|c|}
\hline & \multicolumn{1}{|c|}{1 Quarter Ahead } & \multicolumn{4}{|c|}{ 4 Quarter Ahead } \\
\hline Variable & $a_{0}$ & $a_{1}$ & $R^{2}$ & $a_{0}$ & $a_{1}$ & $R^{2}$ \\
\hline \multicolumn{8}{|c|}{ The United Kingdom } \\
\hline Estimate & 0.02 & 1.43 & 0.05 & 1.09 & 5.25 & 0.15 \\
t-values & 2.21 & 2.13 & 0.04 & 38.78 & 2.43 & 0.14 \\
\hline \multicolumn{8}{|c|}{ Japan } \\
\hline Estimate & 0.01 & 0.59 & 0.02 & 1.01 & 4.18 & 0.15 \\
t-values & 0.68 & 1.13 & 0.00 & 27.88 & 2.86 & 0.14 \\
\hline
\end{tabular}

In Panel A, the following OLS regression is carried out using all observations:

$$
R_{m}(k)-R_{f}(k)=a_{0}+a_{1} C A Y(t-1)+e_{t},
$$

where $R_{m}(k)-R_{f}(k)$ is excess market return $k$ quarters ahead $(k=1,4,16)$ of the current quarter $t$. In Panel $\mathrm{B}$, the following OLS regression is carried out using all observations:

$$
\prod_{i=1}^{K}\left[R_{m}(t+i-1)-R_{f}(t+i-1)\right]=a_{0}+a_{1} C A Y(t-1)+e_{t},
$$

where $\prod_{i=1}^{K}\left[R_{m}(t+i-1)-R_{f}(t+i-1)\right]$ is accumulative excess market return $k$ quarters ahead $(k=1,4,16)$ of the current quarter $t$. As in the literature, estimated one-period lagged CAY is used to capture information currently available to the public. The sample covers 1970:Q3 to 2000:Q3 for the United Kingdom and 1980:Q1 to 2000:Q3 for Japan. We report the estimated regression coefficients in the first row for each country, and the Newey-West HAC $t$-statistics in the second row. The $R^{2}$ in the top row is unadjusted and the $R^{2}$ in the bottom row is adjusted.

the left hand side:

$$
\prod_{k=1}^{k=K}\left[R_{m}(t+k)-R_{f}(t+k)\right]=a_{0}+a_{1} \widehat{\operatorname{cay}}_{t}+e_{t}
$$


FIG. 2. Quarterly excess market return and mimicking portfolio returns versus one-quarter lagged CAY in Japan from 1981:Q1 to 2001:Q4.

FIG. 2a. Excess market return (solid line) versus CAY (broken line).

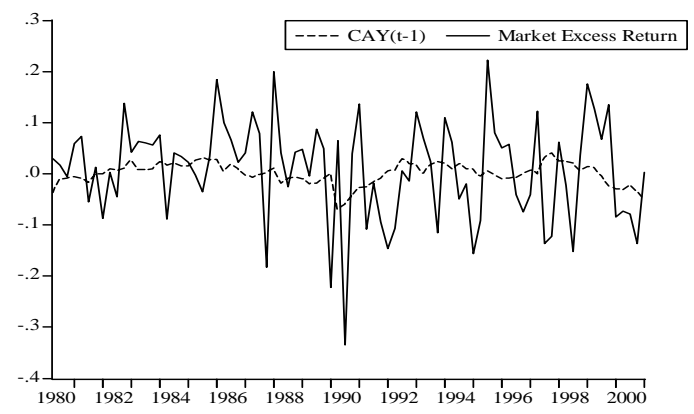

FIG. 2b. High B/M minus low B/M portfolio return (solid line) versus CAY (broken line).

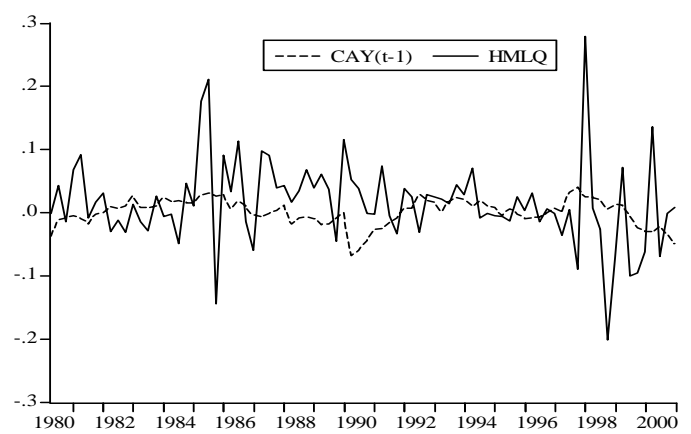

FIG. 2c. Large-size minus small-size portfolio return (solid line) versus CAY (broken line).

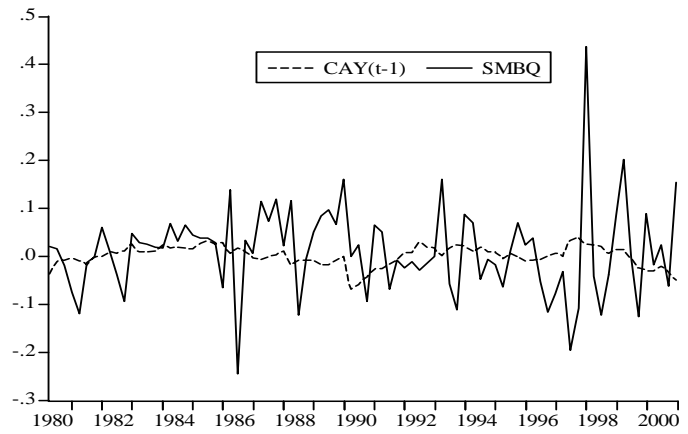

for the case with $K=1$ and 4 . As the panel shows, for both the U.K. and Japan, $\widehat{c a y}$ is able to forecast $K$ quarter accumulative excess market returns with a magnitude of approximately 15 percent. ${ }^{9}$

\footnotetext{
${ }^{9}$ The full-sample regressions presented here provide a measure of in-sample forecasting power of $\widehat{c a y}$. We restrict attention to the in-sample forecastability in this paper as we
} 


\section{THE CROSS-SECTION OF RETURNS AND $\widehat{C A Y}$}

Consider a linear beta representation of a multifactor model conditional on a time $t$ information set $\Omega_{t}$ :

$$
E_{t}\left(R_{i, t+1}\right)=r_{0, t}+\lambda_{t}^{\prime} \beta_{i, t}
$$

where $r_{0, t}$ is the "zero-beta" rate, $\beta_{i, t}$ is the factor loading, and $\lambda_{t}$ is the factor risk premium. Taking unconditional expectation in this conditional linear factor model gives rise to, via the law of iterated expectation,

$$
E\left(R_{i, t+1}\right)=E\left(r_{0, t}\right)+E\left(\lambda_{t}^{\prime}\right) E\left(\beta_{i, t}\right)+\operatorname{cov}\left(\lambda_{t}^{\prime}, \beta_{i, t}\right),
$$

which is a unconditional linear factor model modified by a unconditional covariance term $\operatorname{cov}\left(\lambda_{t}^{\prime}, \beta_{i, t}\right)$. Unless this covariance is zero, which seems to be a questionable assumption, the validity of the conditional model does not imply the validity of the unconditional model. The possible violation of this assumption might have contributed to the failure in the empirical implementation of the unconditional linear asset pricing models. Fama and MacBeth (1973) point to this possibility of model mis-specification as manifested by the portfolio's beta moving around pre- and post- portfolio formation, and Jagannathan and Wang (1996) show that the risk premium and factor betas are indeed correlated in the U.S.

To remedy the problem, research at least since the work by Jagannathan and Wang (1996) has focused on identifying "conditional" variables to capture the information content of the time-varying information set $\Omega_{t}$. Jagannathan and Wang specify risk premium as a linear function of the conditional variables $Z_{t}$, while Cochrane (1996) specifies alternatively the coefficients as linear functions of the conditional variables $Z_{t}$. One important advantage of this latter approach is that it allows one to apply well-recognized estimation and inference techniques such as Fama-MacBeth (1973) procedure. This is the approach that Lettau and Ludvigson (2002b) follow. It is also the approach that we take in the current paper. ${ }^{10}$

The Fama-MacBeth procedure first estimates the factor beta via a timeseries regression using either a full sample period or rolling window method. Given the relatively short horizon of our time-series data, we use full-sample estimation procedure instead of rolling estimation. For each asset $i$, the following regression equation is estimated without using any conditional

are interested only in knowing whether $\widehat{c a y}$ contains useful information about household consumption and investment optimizing behaviors, a question that can be answered by exploring the in-sample nature of the problem.

10 For details in comparing macroeconomic variables as conditional variables (or scaling variable as in Lettau and Ludvigson, 2002b), see Hodrick and Zhang (2001). For details in the econometric treatment, see Cochrane (2001) and Lettau and Ludvigson (2002b). 
variable,

$$
R_{i, t}^{e}=\beta_{0}+\beta^{\prime} \mathbf{F}_{t},
$$

or, the following regression equation is estimated with the conditional variable $z_{t}$ incorporated,

$$
R_{i, t}^{e}=\left(\beta_{0}+z_{t} \widetilde{\beta}_{0}\right)+\left(\beta_{1}^{\prime}+z_{t} \widetilde{\beta}_{1}^{\prime}\right) \mathbf{F}_{t}+\varepsilon_{i, t} .
$$

It then estimates the factor risk premium via a cross-sectional regression at each time $t$ by regressing excess returns $\left(R_{i, t}^{e}\right)$ on the estimated beta factor of asset $i\left(\widehat{\beta}_{i}\right)$,

$$
R_{i, t}^{e}=\lambda_{0, t}+\Gamma_{t}^{\prime} \widehat{\beta}_{i}+e_{i, t},
$$

or, in the conditional setting, it estimates the following model:

$$
R_{i, t}^{e}=\lambda_{0, t}+\Gamma_{t}^{\prime}\left(\widehat{\beta}_{1}^{\prime}+z_{t} \widehat{\widetilde{\beta}_{1}^{\prime}}\right)+e_{i, t} .
$$

The above beta pricing representation is general enough to net many of the familiar asset pricing models. In the case in which the only risk factor $\left(f_{t+1}\right)$ is excess market return, it reduces to the traditional CAPM model; if the only risk factor is the consumption growth rate, then it corresponds to the consumption-based CAPM (CCAPM) model; if there are multiple risk factors, such as excess market return and labor income growth, then it leads to the human-capital augmented CAPM (HC-CAPM) model; while if the risk factors include the mimicking portfolio returns, like the HML, SMB portfolio returns, in addition to excess market return, then it gives rise to the Fama-French (FF) three-factor model. With some mild assumptions, the pricing kernel can also be modified into

$$
M_{t+1}=\lambda_{0}+\left(\boldsymbol{\Gamma}_{1}^{\prime}+z_{t} \boldsymbol{\Gamma}_{2}^{\prime}\right) \mathbf{F}_{t+1}
$$

which involves a time-varying parameter set $\left(\boldsymbol{\Gamma}_{1}^{\prime}+z_{t} \boldsymbol{\Gamma}_{2}^{\prime}\right)$, even though $\boldsymbol{\Gamma}_{1}$ and $\boldsymbol{\Gamma}_{2}$ can no longer be interpreted as factor betas.

\subsection{Setup of Empirical Testing Models}

For each country $j$, we estimate the following models using the FamaMacBeth procedure, which allows us to handle the econometric issues associated with a small sample. In what follows, $R_{i, t}$ denotes the $i$-th FamaFrench size and book-to-market equity double sorted portfolio return, $M_{t}$ denotes the return to market index, and $R F_{t}$ denotes the risk free interest rate. The following models are consider in turn. 
(1) The classical CAPM:

$$
R_{i, t}-R F_{t}=a_{0}+a_{1}\left[M_{t}-R F_{t}\right]+\epsilon_{t}
$$

(2) The three-factor Fama-French model:

$$
R_{i, t}-R F_{t}=a_{0}+a_{1}\left[M_{t}-R F_{t}\right]+a_{2}\left[H M L_{t}\right]+a_{3}\left[S M B_{t}\right]+\epsilon_{t}
$$

(3) The classical CAPM with $\widehat{c a y}_{t-1}$ as the scaling variable:

$$
R_{i, t}-R F_{t}=a_{0}+a_{1}\left[M_{t}-R F_{t}\right]+a_{2} \widehat{c a y}_{t-1}+a_{3}\left[M_{t}-R F_{t}\right] \cdot \widehat{c a y}_{t-1}+\epsilon_{t}
$$

(4) The human-capital augmented CAPM (HC-CAPM) with $\widehat{c a y}_{t-1}$ as the scaling variable:

$$
\begin{aligned}
R_{i}-R F_{t} & =a_{0}+a_{1}\left[M_{t}-R F_{t}\right]+a_{2} \widehat{\operatorname{cay}}_{t-1}+a_{3}\left[\Delta y_{t}\right] \\
& +a_{4}\left[M_{t}-R F_{t}\right] \cdot \widehat{c a y}_{t-1}+a_{5}\left[\Delta y_{t}\right] \cdot \widehat{c a y}_{t-1}+\epsilon_{t}
\end{aligned}
$$

Here we also estimate the HC-CAPM without $\widehat{c a y}_{t-1}$ in the intercept term.

(5) The consumption CAPM (CCAPM) with $\overline{\mathrm{cay}}_{t-1}$ as the scaling variable:

$$
R_{i}-R F_{t}=a_{0}+a_{1} \widehat{\operatorname{cay}}_{t-1}+a_{2}\left[\Delta c_{t}\right]+a_{3}\left[\Delta c_{t}\right] \cdot \widehat{\operatorname{cay}}_{t-1}+\epsilon_{t}
$$

and with or with-out $\widehat{c a y}_{t-1}$ in the intercept term.

\section{2. $\quad$ Testing Results}

To examine the performance of alternative beta representations, we first estimate the traditional CAPM, the consumption-based CAPM (CCAPM), the human-capital augmented CAPM (HC-CAPM), with and without the scaling variables. Table VI summarizes some key discussions of our estimated factor loadings $\lambda$, the original Fama-MacBeth t-statistics, the tstatistics with Shanken's corrections, as well as the adjusted $R^{2}$ from the second pass cross-sectional regressions using the Fama-MacBeth procedure.

Some inferences about the models' empirical performance alluded to in the table based on U.K. and Japanese data conform to some familiar results obtained in the previous studies based on U.S. data. The CAPM without the conditional variable and labor income growth rate factor performs poorly in explaining the cross-sectional returns for both the U.K. and Japan, as manifested by the low adjusted $R^{2}$ and the statistically insignificant coefficient of excess market return. For the U.K., the coefficient of excess market return even has a negative sign, contrary even qualitatively to what theory would suggest. This failure of the model can also be seen in Figure 3 - the predicted return and the realized return do not 
TABLE 6.

Fama-MacBeth Cross-Sectional Regression Evidence

Panel A: Fama-MacBeth Cross Sectional Regressions for the United Kingdom with and without CAY as the Scaling Variable

\begin{tabular}{|c|c|c|c|c|c|c|c|c|c|c|}
\hline CONT. & $E M R Q_{t}$ & $H M L Q_{t}$ & $S M B Q_{t}$ & $\overline{D R C O N_{t}}$ & $D R I N C_{t}$ & $C A Y_{t-1}$ & $\begin{array}{l}E M R Q_{t} \\
* C A Y_{t-1}\end{array}$ & $\begin{array}{l}D R C O N_{t} \\
* C A Y_{t-1}\end{array}$ & $\begin{array}{l}D R I N C_{t} \\
* C A Y_{t-1}\end{array}$ & $R^{2}$ \\
\hline \multicolumn{11}{|c|}{ Model 1: Classical CAPM } \\
\hline $\begin{array}{c}4.98 \\
2.43(1.67)\end{array}$ & \begin{tabular}{|c|}
-2.51 \\
$-1.21(-0.98)$
\end{tabular} & & & & & & & & & $\begin{array}{l}0.15 \\
0.09\end{array}$ \\
\hline
\end{tabular}

Model 2: Fama-French 3 Factor Model

\begin{tabular}{|c|c|c|c|c|c|c|c|c|}
\hline 2.17 & -0.32 & 1.37 & 0.61 & & & & & \\
$1.64(1.43)$ & $-0.20(-0.20)$ & $2.85(2.27)$ & $1.02(0.81)$ & & & & & \\
\hline
\end{tabular}

Model 3: Consumption-based CAPM

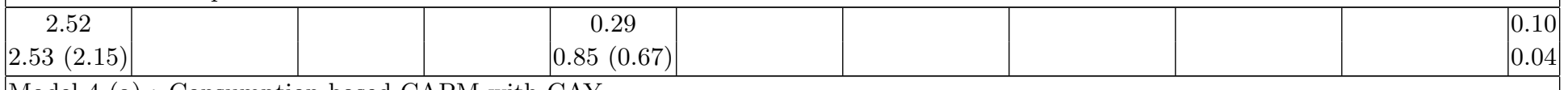

Model 4 (a) : Consumption-based CAPM with CAY

\begin{tabular}{|c|c|c|c|c|c|c|}
\hline $\begin{array}{c}1.28 \\
1.35(0.84)\end{array}$ & & 0.63 & -0.55 & -0.02 & 0.47 \\
$1.91(1.11)$ & & $-1.33(-0.85)$ & $-2.32(-1.43)$ & 0.34 \\
\hline
\end{tabular}

\begin{tabular}{|c|c|c|c|c|c|}
\hline $\begin{array}{c}1.38 \\
1.35(0.83) \\
\end{array}$ & & \begin{tabular}{|c|}
0.64 \\
$1.91(1.12)$
\end{tabular} & & $\begin{array}{c}-0.02 \\
-2.29(-1.43)\end{array}$ & $\begin{array}{l}0.47 \\
0.39 \\
\end{array}$ \\
\hline \multicolumn{6}{|c|}{ Model 5: Human Capital Augmented CAPM } \\
\hline $\begin{array}{c}5.09 \\
3.16(2.14)\end{array}$ & $\begin{array}{c}-2.60 \\
-1.47(-1.23)\end{array}$ & & $\begin{array}{c}-0.10 \\
-0.14(-0.12)\end{array}$ & & \begin{tabular}{|l|}
0.15 \\
0.02
\end{tabular} \\
\hline
\end{tabular}

Model 6: Human Capital Augmented CAPM with CAY

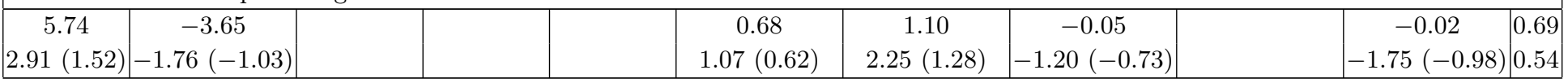

Model 6 (b): Human Capital Augmented CAPM with CAY (without CAY in the intercept term)

\begin{tabular}{|c|c|c|c|c|c|c|c|c|}
\hline 4.33 & -2.06 & & & 1.06 & -0.11 & & 0.52 \\
$2.35(1.29)$ & $-1.06(-0.66)$ & & & & $1.54(0.90)$ & & $-2.42(-1.45)$ & \\
\hline
\end{tabular}

come even close. The CCAPM without the conditional variable and laborincome growth rate factor works even worse for the U.K. and fairs only slightly better for Japan. In the end, neither of the two models performs well in pricing the cross-sectional returns for these two countries.

The performance of the HC-CAPM without the conditional variable, as originally presented in Jagannathan and Wang (1996), is mixed. It works significantly better than the (C)CAPM for Japan where the lagged laborincome growth factor is highly significant and the adjusted $R^{2}$ is as great as 45 percent (see, also, Jagannathan et al., 1998). Yet, it fairs no better than the (C)CAPM for the U.K., where the lagged labor-income growth is not significantly statistically different from zero and the adjusted $R^{2}$ is 
Panel B: Fama-MacBeth Cross-Sectional Regressions for Japan with and without CAY as the Scaling Variable

\begin{tabular}{|c|c|c|c|c|c|c|c|c|c|c|}
\hline CONT. & $E M R Q_{t}$ & $H M L Q_{t}$ & $S M B Q_{t}$ & $D R C O N_{t}$ & $D R I N C_{t}$ & $C A Y_{t-1}$ & $\begin{array}{l}E M R Q_{t} \\
* C A Y_{t-1}\end{array}$ & $\begin{array}{l}D R C O N_{t} \\
* C A Y_{t-1}\end{array}$ & $\begin{array}{l}D R I N C_{t} \\
* C A Y_{t-1} \\
\end{array}$ & $R^{2}$ \\
\hline \multicolumn{11}{|c|}{ Model 1: Classical CAPM } \\
\hline $\begin{array}{c}-7.27 \\
-1.16(-0.88)\end{array}$ & $\begin{array}{c}6.87 \\
1.05(0.80)\end{array}$ & & & & & & & & & $\begin{array}{l}0.11 \\
0.07\end{array}$ \\
\hline \multicolumn{11}{|c|}{ Model 2: Fama-French 3 Factor Model } \\
\hline $\begin{array}{c}-1.17 \\
-0.44(-0.37)\end{array}$ & $\begin{array}{c}0.48 \\
0.17(0.15)\end{array}$ & \begin{tabular}{|c|}
2.24 \\
$3.43(2.88)$
\end{tabular} & $\begin{array}{c}0.87 \\
0.95(0.88)\end{array}$ & & & & & & & $\begin{array}{l}0.75 \\
0.72\end{array}$ \\
\hline $\begin{array}{c}-0.48 \\
-0.38(-0.21)\end{array}$ & & & & $\begin{array}{c}1.37 \\
1.86(1.01)\end{array}$ & & & & & & $\begin{array}{l}0.15 \\
0.11\end{array}$ \\
\hline \multicolumn{11}{|c|}{ Model 4 (a): Consumption-based CAPM with CAY } \\
\hline $\begin{array}{c}-0.69 \\
-0.50(-0.24)\end{array}$ & & & & \begin{tabular}{|c|}
1.53 \\
$2.64(1.23)$
\end{tabular} & & $\begin{array}{c}-0.35 \\
-0.31(-0.15)\end{array}$ & & $\begin{array}{c}0.01 \\
0.97(0.49)\end{array}$ & & $\begin{array}{l}0.25 \\
0.15\end{array}$ \\
\hline $\begin{array}{c}-4.09 \\
-0.66(-0.41)\end{array}$ & $\begin{array}{c}3.63 \\
0.56(0.35)\end{array}$ & & & & $\left|\begin{array}{c}2.11 \\
2.76(1.75)\end{array}\right|$ & & & & & $\begin{array}{l}0.49 \\
0.45\end{array}$ \\
\hline \multicolumn{11}{|c|}{ Model 6 (a): Human Capital Augmented CAPM with CAY } \\
\hline $\begin{array}{c}-3.64 \\
-1.46(-0.90) \\
\end{array}$ & $\begin{array}{c}3.12 \\
1.17(0.70) \\
\end{array}$ & & & & \begin{tabular}{|c|}
2.05 \\
$2.58(1.61)$
\end{tabular} & \begin{tabular}{|c|}
1.11 \\
$1.46(0.76)$ \\
\end{tabular} & & \begin{tabular}{|c|}
-0.03 \\
$-0.29(-0.18)$ \\
\end{tabular} & $\begin{array}{c}0.00 \\
0.19(0.12) \\
\end{array}$ & $\begin{array}{l}0.56 \\
0.45 \\
\end{array}$ \\
\hline \multicolumn{11}{|c|}{ Model 6 (b): Human Capital Augmented CAPM with CAY (without CAY in the intercept term) } \\
\hline $\begin{array}{c}0.15 \\
0.05(0.03)\end{array}$ & $\begin{array}{c}-0.66 \\
-0.22(-0.15)\end{array}$ & & & & \begin{tabular}{|c|}
2.00 \\
$2.49(1.70)$
\end{tabular} \mid & & $\begin{array}{c}0.11 \\
0.95(0.64)\end{array}$ & & $\begin{array}{c}0.00 \\
-0.24(-0.17)\end{array}$ & $\begin{array}{l}0.53 \\
0.43\end{array}$ \\
\hline
\end{tabular}

In this table, cross-sectional regressions (with an intercept term in the second stage cross-sectional regression) outcomes and test statistics from the second stage Fama-MacBeth procedures are shown. The regression coefficients (multiplied by 100) are in the first row of each model, the second raw shows Fama-MacBeth t-statistics, and the $t$-statistics after Shanken's corrections (in the bracket). For the $R^{2}$ statistics, the first row shows the unadjusted, and the second row shows the adjusted. For the calculation of Shanken's correction term, West and Newey HAC estimator is used based upon the optimal truncation criterion proposed by Newey.

also low. That said, one needs to apply caution when comparing the results presented here to those reported in Jagannathan and Wang or Jagannathan et al. that examines a sample period slightly different than ours. These previous studies of HC-CAPM use monthly data, which may contain many transitory components of labor-income growth rates within a quarter and thus be subject to greater measurement errors. This measurement concern may be strengthened by the statistical revisions to the macroeconomic variables which are not taken into account by these studies. In any case, there is a lack of empirical investigation in the performance of HC-CAPM 
FIG. 3. Realized (horizontal axis) versus various models' predicted returns of FamaFrench size/market-to-equity doubled sorted portfolios (vertical axis).

FIG. 3a. The United Kingdom.
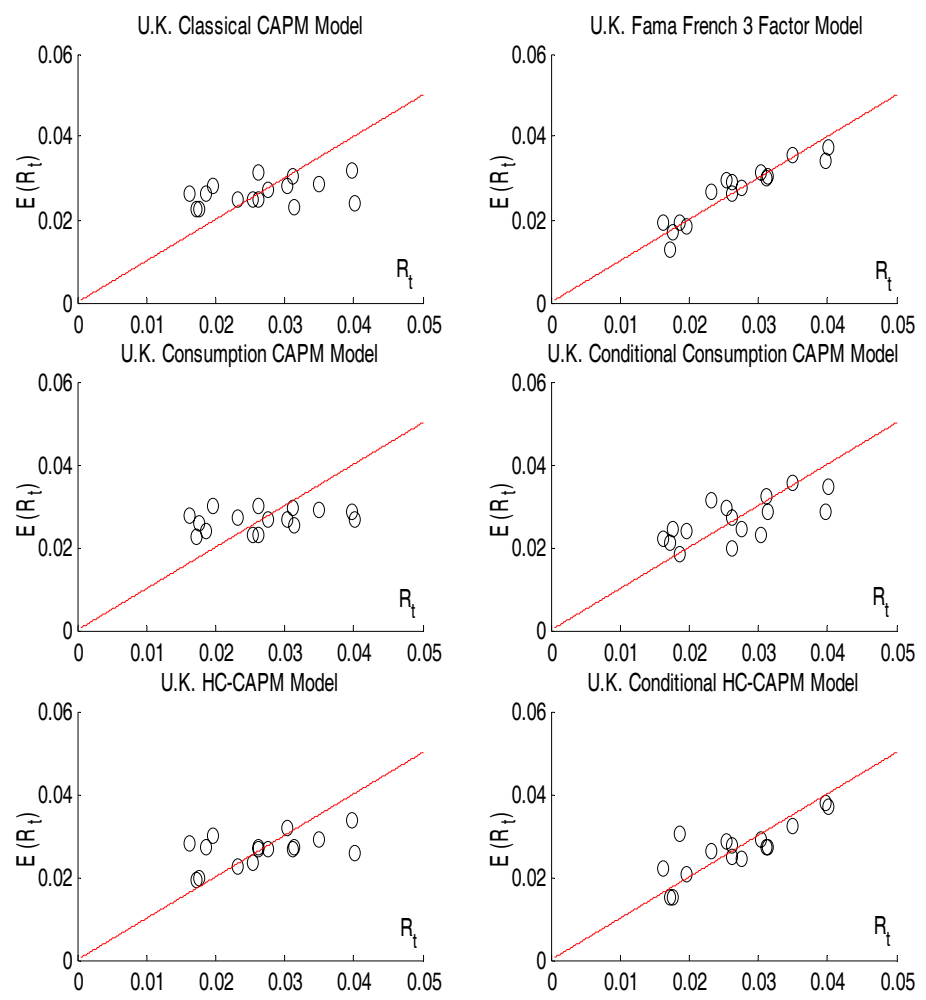

based on U.K. data that can be compared against our results presented here.

Table VII contains our results from running the Fama-MacBeth regressions within the Fama-French three-factor model. These results confirm the empirical success of the three-factor model, in particular, the importance of the book-to-market equity in explaining the cross-section of average stock returns. For both the U.K. and Japan, the model explains much more of the cross-sectional returns (over $80 \$$ percent for the U.K. and over $70 \$$ percent for Japan) than the various versions of CAPM. ${ }^{11}$ The book-to-market effect is stronger than the size effect. When both $H M L Q$ and $S M B Q$ factors are

\footnotetext{
${ }^{11}$ These results are broadly consistent with the findings by Fama and French (1998), who explore the value premium in major developed countries and the size premium in a dozen of emerging markets.
} 
FIG. 3b. Japan.
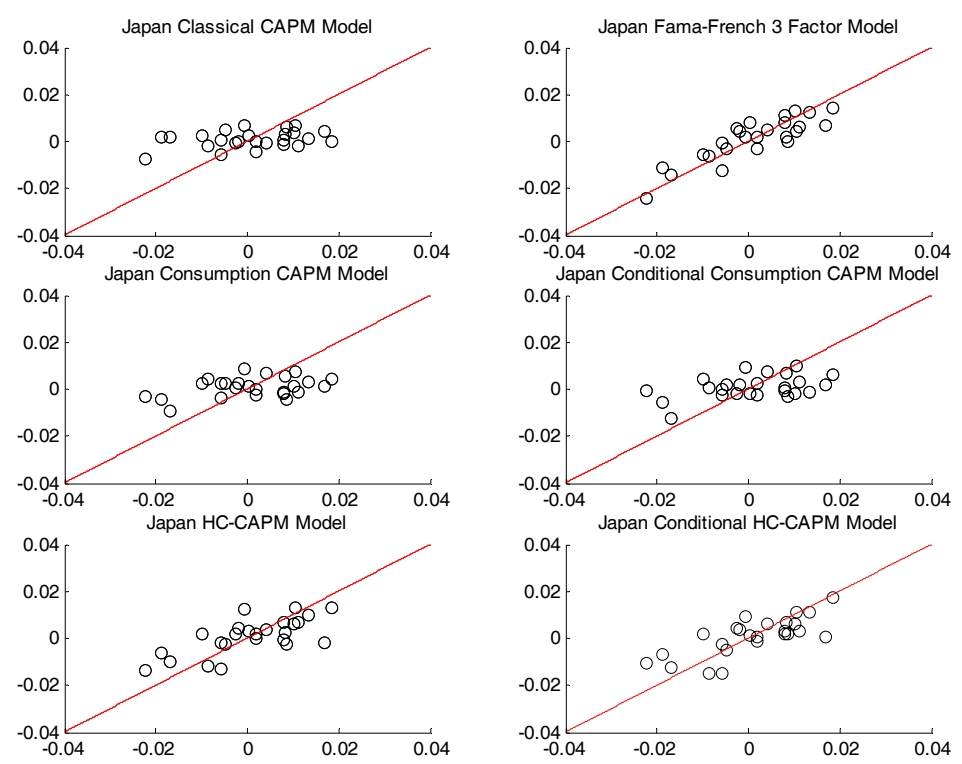

included in the regression, the average book-to-market slope $(H M L Q)$ is 2.85 standard errors from 0 for the U.K. and 3.43 standard errors from 0 for Japan. Note that the $H M L Q$ factor remains highly significant even after correcting for the sampling errors in the $\beta$ 's due to first-pass estimation: it is 2.27 standard errors from 0 for the U.K. and 2.88 standard errors from 0 for Japan.

The paper's main results are contained in the rest of Table VII, which illustrates the contribution of $\widehat{c a y}$ as a conditioning variable to improving the performance of the various asset-pricing models. Due to the fact that some relevant macroeconomic data may only be available with a delay, we follow the tradition in the literature to use the lagged $\widehat{c a y}$ as the conditioning variable in our baseline Fama-MacBeth regressions. ${ }^{12}$ The table presents the average and aggregated portfolios' pricing errors, as well as the chi-square $\left(\chi^{2}\right)$ statistics for the testing of the hypothesis that the pricing errors are jointly zero. Under the assumption that the errors in the first-stage Fama-MacBeth regressions are independently and identically

\footnotetext{
${ }^{12}$ Given that more information is contained in the concurrent $\widehat{c a y}$, it is not surprising that we find that our results are generally strengthened (i.e., the cross-sectional regression's fitness improves and the pricing errors decline) when the concurrent $\widehat{c a y}$ is used as the conditioning variable.
} 
TABLE 7.

Portfolio Pricing Errors

Panel A: Pricing Errors for 16 Fama-French Portfolios in the U.K

\begin{tabular}{|c|c|c|c|c|c|c|}
\hline Portfolios & CAPM & $\begin{array}{c}\text { Fama- } \\
\text { French }\end{array}$ & CCAPM & $\begin{array}{c}\text { CCAPM } \\
\text { with CAY }\end{array}$ & HC-CAPM & $\begin{array}{c}\text { HC-CAPM } \\
\text { with CAY }\end{array}$ \\
\hline \multirow{2}{*}{ S1B1 } & -0.8809 & 0.0988 & -1.0242 & -0.4570 & -0.8617 & -0.1226 \\
S1B2 & -0.5104 & -0.2817 & -0.3522 & -0.1044 & -0.4932 & -0.1303 \\
S1B3 & 0.0885 & 0.1000 & 0.1529 & -0.1286 & 0.0981 & 0.3985 \\
S1B4 & 0.7832 & 0.5568 & 1.1170 & 1.1312 & 0.7524 & 0.2068 \\
S2B1 & -1.0314 & -0.3294 & -1.1347 & -0.5745 & -1.0086 & -0.5533 \\
S2B2 & 0.0394 & -0.0026 & 0.0632 & 0.3030 & 0.0463 & 0.3139 \\
S2B3 & 0.2203 & -0.1258 & 0.3352 & 0.7311 & 0.2173 & 0.1211 \\
S2B4 & 0.6515 & -0.0813 & 0.6106 & -0.0813 & 0.6405 & 0.2381 \\
S3B1 & -0.5186 & 0.0823 & -0.8325 & -0.6710 & -0.5068 & 0.2214 \\
S3B2 & -0.1920 & -0.3674 & -0.4052 & -0.8262 & -0.1650 & -0.3170 \\
S3B3 & 0.8219 & 0.1122 & 0.6041 & 0.2760 & 0.8238 & 0.4303 \\
S3B4 & 1.6023 & 0.2915 & 1.3544 & 0.5270 & 1.6471 & 0.3466 \\
S4B1 & -0.5166 & 0.4499 & -0.5254 & -0.3757 & -0.5387 & 0.2349 \\
S4B2 & -0.7491 & -0.0938 & -0.5294 & 0.0026 & -0.7563 & -1.1882 \\
S4B3 & 0.1155 & -0.0049 & 0.3273 & 0.6553 & 0.0675 & 0.1215 \\
S4B4 & 0.0765 & -0.4045 & 0.2391 & -0.4075 & 0.0374 & -0.3218 \\
\hline \multicolumn{7}{|c|}{ Pricing Errors of Aggregated Portfolios } \\
\hline S1 & 0.0129 & 0.0064 & 0.0156 & 0.0123 & 0.0125 & 0.0048 \\
S2 & 0.0124 & 0.0036 & 0.0133 & 0.0098 & 0.0122 & 0.0069 \\
S3 & 0.0188 & 0.0049 & 0.0175 & 0.0122 & 0.0192 & 0.0067 \\
S4 & 0.0092 & 0.0061 & 0.0085 & 0.0086 & 0.0093 & 0.0126 \\
B1 & 0.0154 & 0.0057 & 0.0182 & 0.0106 & 0.0152 & 0.0065 \\
B2 & 0.0093 & 0.0047 & 0.0076 & 0.0089 & 0.0092 & 0.0128 \\
B3 & 0.0086 & 0.0020 & 0.0078 & 0.0103 & 0.0086 & 0.0061 \\
B4 & 0.0190 & 0.0075 & 0.0187 & 0.0132 & 0.0192 & 0.0057 \\
\hline Average & 0.0132 & 0.0051 & 0.0134 & 0.0107 & 0.0132 & 0.0078 \\
-statistics & $33.89^{*}$ & 22.04 & $37.56^{*}$ & $34.42^{*}$ & $28.91^{*}$ & 20.83 \\
\hline
\end{tabular}

distributed over time, the test statistic is given by

$$
\left(1+\lambda^{\prime} \widehat{\Sigma}_{f}^{-1} \lambda\right)^{-1} \widehat{\varepsilon}_{F M} \operatorname{cov}\left(\widehat{\varepsilon}_{F M}\right) \widehat{\varepsilon}_{F M} \sim \chi_{N-K}^{2}
$$

where the term $\left(1+\lambda^{\prime} \widehat{\Sigma}_{f}^{-1} \lambda\right)$ reflects Shanken's corrections (Shanken 1992) to account for the sampling errors in estimating the beta vectors via the 
Panel B: Pricing Errors for 25 Fama-French Portfolios in Japan

\begin{tabular}{|c|c|c|c|c|c|c|}
\hline Portfolios & CAPM & $\begin{array}{c}\text { Fama- } \\
\text { French }\end{array}$ & CCAPM & $\begin{array}{c}\text { CCAPM } \\
\text { with CAY }\end{array}$ & HC-CAPM & $\begin{array}{c}\text { HC-CAPM } \\
\text { with CAY }\end{array}$ \\
\hline \multicolumn{7}{|c|}{ Individual Portfolio Pricing Errors } \\
\hline S1B1 & 0.2505 & 0.8873 & 1.3079 & 1.1905 & 1.2117 & 0.9707 \\
S1B2 & 0.5054 & 0.6348 & 0.2608 & 0.1904 & 0.5755 & 0.3642 \\
S1B3 & 1.2675 & 1.0156 & 1.5416 & 1.4901 & 1.8611 & 1.6782 \\
S1B4 & 0.6955 & 0.0021 & 0.9314 & 0.8478 & 0.8204 & 0.5688 \\
S1B5 & 1.8351 & 0.4065 & 1.4236 & 1.2109 & 0.6603 & 0.3169 \\
S2B1 & -1.2536 & -0.4153 & -1.2502 & -1.4369 & -1.1990 & -1.2644 \\
S2B2 & -0.7599 & -0.2498 & -0.9126 & -1.0110 & -1.2025 & -0.9364 \\
S2B3 & 0.3894 & 0.5882 & 0.2992 & 0.0584 & -0.0964 & 0.1218 \\
S2B4 & 0.4703 & -0.1193 & -0.2786 & -0.3192 & -0.0746 & -0.2822 \\
S2B5 & 1.2270 & 0.0880 & 1.0203 & 1.4206 & 0.1232 & -0.0955 \\
S3B1 & -2.0493 & -0.7640 & -1.4679 & -1.3139 & -1.3489 & -1.5490 \\
S3B2 & -0.9744 & -0.1711 & -0.7367 & -0.6788 & -0.1926 & -0.0582 \\
S3B3 & -0.2053 & -0.6175 & -0.4321 & -0.3922 & -0.6563 & -0.6314 \\
S3B4 & -0.1851 & -0.8526 & -0.3239 & -0.0701 & -0.6241 & -0.8103 \\
S3B5 & 0.6625 & -0.2601 & 0.9063 & 1.1890 & 0.3364 & 0.4210 \\
S4B1 & -1.8558 & -0.2479 & -0.7840 & -0.4452 & -0.6668 & -0.4962 \\
S4B2 & -0.7041 & -0.2427 & -1.2786 & -0.9593 & -0.0079 & 0.0693 \\
S4B3 & -0.6416 & -0.5145 & -0.8435 & -0.5598 & -0.4682 & -0.2910 \\
S4B4 & 0.1994 & -0.0114 & 0.2007 & 0.4484 & 0.1905 & 0.3233 \\
S4B5 & -0.2480 & -0.7759 & -0.1176 & 0.2080 & -0.3352 & -0.1489 \\
S5B1 & -1.4763 & 0.2114 & -1.9294 & -2.1526 & -0.6471 & -0.7672 \\
S5B2 & -0.0079 & 0.6828 & -0.2306 & -0.3549 & 0.7810 & 0.8845 \\
S5B3 & 0.6234 & 0.5365 & 0.4482 & -0.0719 & 0.2088 & 0.4589 \\
S5B4 & 1.3074 & 0.5275 & 1.2496 & 0.8065 & 0.5561 & 0.8378 \\
S5B5 & 0.9279 & -0.3385 & 0.9962 & 0.7049 & 0.1945 & 0.3154 \\
\hline
\end{tabular}

time-series regressions, $\sum_{f}$ is the variance-covariance matrix of the factors, $\widehat{\varepsilon}_{F M}$ is the estimated pricing errors vector, $N$ is the number of pricing assets (in our current case, $N=16$ for the U.K. and $N=25$ for Japan), and $K$ is the number of factors in a given model (in our current case, $K$ is determined by the different beta representations). ${ }^{13}$

\footnotetext{
${ }^{13}$ Empirical asset pricing models featuring macroeconomic variables typically generate large estimation errors in the first-stage Fama-MacBeth regressions, and consequently the t-statistics for the cross-sectional regression's coefficients are typically small and the $\chi^{2}$-statistics are biased downwards (e.g., Jagannathan and Wang (1996) and Lettau and Ludvigson (2002b). In some unreported tests, we find that we cannot reject the null that the CCAPM or the HC-CAPM with $\widehat{c a y}$ as a conditioning variable has pricing errors statistically insignificantly different from zero while the Fama-French three factor
} 


\begin{tabular}{|c|c|c|c|c|c|c|}
\hline Portfolios & CAPM & $\begin{array}{c}\text { Fama- } \\
\text { French }\end{array}$ & CCAPM & $\begin{array}{c}\text { CCAPM } \\
\text { with CAY }\end{array}$ & HC-CAPM & $\begin{array}{c}\text { HC-CAPM } \\
\text { with CAY }\end{array}$ \\
\hline \multicolumn{7}{|c|}{ Pricing Errors of Aggregated Portfolios } \\
\hline S1 & 0.0240 & 0.0154 & 0.0266 & 0.0242 & 0.0252 & 0.0208 \\
S2 & 0.0201 & 0.0078 & 0.0190 & 0.0228 & 0.0171 & 0.0161 \\
S4 & 0.0238 & 0.0134 & 0.0195 & 0.0194 & 0.0167 & 0.0191 \\
S5 & 0.0211 & 0.0099 & 0.0174 & 0.0129 & 0.0090 & 0.0068 \\
B1 & 0.0227 & 0.0109 & 0.0256 & 0.0243 & 0.0119 & 0.0154 \\
B2 & 0.0338 & 0.0128 & 0.0312 & 0.0317 & 0.0236 & 0.0240 \\
B3 & 0.0151 & 0.0101 & 0.0177 & 0.0160 & 0.0156 & 0.0134 \\
B4 & 0.0161 & 0.0152 & 0.0189 & 0.0164 & 0.0204 & 0.0188 \\
S5 & 0.0158 & 0.0101 & 0.0163 & 0.0130 & 0.0119 & 0.0137 \\
B1 & 0.0227 & 0.0109 & 0.0256 & 0.0243 & 0.0119 & 0.0154 \\
B2 & 0.0338 & 0.0128 & 0.0312 & 0.0317 & 0.0236 & 0.0240 \\
B3 & 0.0151 & 0.0101 & 0.0177 & 0.0160 & 0.0156 & 0.0134 \\
B4 & 0.0161 & 0.0152 & 0.0189 & 0.0164 & 0.0204 & 0.0188 \\
B5 & 0.0158 & 0.0101 & 0.0163 & 0.0130 & 0.0119 & 0.0137 \\
\hline Average & 0.0250 & 0.0098 & 0.0221 & 0.0233 & 0.0085 & 0.0064 \\
Pricing Errors & 0.0217 & 0.0115 & 0.0214 & 0.0204 & 0.0160 & 0.0154 \\
$\chi^{2}$-statistics & $50.52^{*}$ & $38.92^{*}$ & $50.27^{*}$ & $50.23^{*}$ & $50.25^{*}$ & $49.81^{*}$ \\
\hline
\end{tabular}

The main message conveyed in the table is that $\widehat{c a y}$ as a conditioning variable improves the pricing ability of virtually all of the models under consideration. Nevertheless, the degree of the improvement is not the same across models or countries. The result is more striking for the U.K., where the HC-CAPM works better than the CCAPM (somewhat in contrast to Lettau and Ludvigson's findings based on U.S. data) and it has the highest adjusted $R^{2}$ and lowest pricing errors among all models. As a matter of fact, without Shanken's corrections, the only models that have pricing errors not significantly statistically different from zero are the HC-CAPM and the Fama-French three-factor model. The portfolio pricing error decomposition provides consistent evidence that the HC-CAPM does a very good job in pricing the portfolios that prove to be difficult to price in general, such as the small size and high book-to-market equity portfolios. It is worth noting that the pattern in the pricing errors of both the HC-CAPM and the CCAPM are broadly similar to the pattern in the pricing errors of the three-factor model.

model has pricing errors statistically significantly different from zero. Given the small sample problem that motivates Shanken's corrections in the first place, one needs to apply caution when inferring from the $\chi^{2}$-statistics about the models' pricing errors. 
Notwithstanding the improvement in the models' pricing ability for Japan, the result obtained here is relatively less striking than that based on U.K. data. On one account, the evidence obtained based on Japanese data tends to reject the null hypothesis of no joint pricing errors for the models under consideration, as in the case without $\widehat{c a y}$ being used as a conditioning variable, though at a less significant level. Similar to the case for the U.K. (and consistent with Lettau and Ludvigson's findings based on U.S. data), including $\widehat{c a y}$ as a conditioning variable improves the pricing ability of the CCAPM, though the HC-CAPM still does a better job, just as in the case without $\widehat{c a y}$. Nevertheless, the gain in having $\widehat{c a y}$ as a conditioning variable within the HC-CAPM is relatively smaller for Japan than for the U.K., as suggested by the significance level of the scaling variables and the multiplicative terms of scaling variables. This weakening in the result based on Japanese data may be a consequence of the mismatch between our constructed measure of $\widehat{c a y}$ for Japan and one implied by the theory. Recall that, due to a caveat in data availability and data quality, we have used Japanese household financial wealth to proxy its total household networth, and in doing so we have excluded its real estate wealth that was subject to some dramatic development of and burst in bubbles from 1980s to 1990 s which might have had significant impacts on its household networth and behavior (see, also, Footnote 5). The measurement issue may be complicated by the fact that Japanese macroeconomic time series have gone through substantial revisions since 1970s.

The delicacy in constructing a theory consistent measure of $\widehat{c a y}$ for eliciting its information content, as manifested by the case of Japan versus that of the U.K., lends some empirical support to the theoretical implication that $\widehat{c a y}$ is an informative rather than spurious variable containing valuable information regarding household behavior. To drive the point home, we turn now to examining in more detail the contribution of $\widehat{c a y}$ as a conditioning variable in the models under consideration to explaining the cross-section of stock returns in the U.K. and Japan. To facilitate our analysis while helping connect to the literature, we conduct cross-sectional regressions under different model specifications using $\widehat{c a y}$ as a conditioning variable as opposed to using an alternative variable, tay, constructed using calender time in place of consumption.

\subsection{The Cross-Section of Returns: $\widehat{\operatorname{cay}}$ versus $\widehat{\operatorname{tay}}$ as a Condi- tioning Valuable}

Some recent debates raise doubt about the information content of $\widehat{c a y}$. For instance, Avramov (2002) and Brennan and Xia (2002) caution against the interpretation of $\widehat{c a y}$ as a conditioning variable in forecasting future stock returns, mainly on three grounds. First, the cointegrating relationship among household consumption, income, and wealth may not be stable 
over time, and the estimation procedure may be subject to misspecification error. Second, the estimation of $\widehat{c a y}$ using full sample data may be subject to a "look-ahead" bias. Third, the forecastability of $\widehat{c a y}$ may be spurious given that the market index, consumption, labor income, and household wealth may share the same time trend. To make their point, Brennan and Xia carefully designed a mechanical measure called $\widehat{t a y}_{t}$, which is the residual from running the following OLS regression based on a full sample:

$$
t=a_{0}+\beta_{a} a_{t}+\beta_{y} y_{t}
$$

where $t$ is the calendar time, $a_{t}$ is the aggregate household wealth and $y_{t}$ is the labor income. Therefore, $\widehat{t a y}$ is constructed in a way similar to how $\widehat{c a y}$ is constructed, while it is calender time that is used in place of consumption. They show that $\widehat{t a y}$ so constructed tracks both excess market return and $\widehat{c a y}$ closely and argue that this provides evidence to suggest that $\widehat{c a y}$ 's empirical success in helping forecast future stock returns in-sample might simply be attributed to a "look-ahead" bias introduced by the use of a full sample in estimating the cointegration parameters. They drive their point home further by showing that neither $\widehat{c a y}$ nor $\widehat{t a y}$ possesses much out-of-sample forecasting ability. Lettau and Ludvigson (2001a) offer arguments to address the issue of the "look-ahead" bias and Lettau and Ludvigson (2002) provide arguments to address the concern over the stability of the cointegration relationship among household consumption, income, and wealth. They emphasize, in particular, a major test power problem to which the kind of cross-time out-of-sample test by Brennan and Xia is likely to be subject owing to the lack of sufficient quarterly time series observations. Both Brennan and Xia and Lettau and Ludvigson base their evidence on U.S. data.

Our results presented in the previous sections based on U.K. and Japanese data suggest that $\widehat{c a y}$ may be a useful conditioning variable in forecasting future stock returns. In this section, we contrast the performance of $\widehat{c a y}$ and $\widehat{t a y}$ as a conditioning variable in explaining the cross-section of stock returns for the U.K. and Japan. To do so, in our second-stage cross-sectional regressions, we also use $\widehat{t a y}$ constructed for the U.K. and Japan in place of the corresponding $\widehat{c a y}$ in the models under consideration. The kind of cross-country out-of-sample tests carried out here gives rise to further evidence supporting the theoretical implication that $\widehat{c a y}$ may contain important information concerning economic fundamentals, as we show now.

We proceed by first constructing the $\widehat{t a y}$ measure for the U.K. and Japan following the procedure proposed by Brennan and Xia. For the U.K., the estimated regression equation based on the sample of $1970 Q 1$ to $2000 Q 3$ is

$$
t=\underset{(-51.18)}{-794.38}-\underset{(-1.80)}{7.31} a+\underset{(20.38)}{161.28 y}, \bar{R}^{2}=0.98
$$


while for Japan, the estimated regression equation based on the sample of $1980 Q 1$ to $2001 Q 1$ is

$$
t=\underset{(-7.37)}{1063.11}+\underset{(3.39)}{54.46 a}+\underset{(0.67)}{20.98 y}, \bar{R}^{2}=0.95
$$

where $t, a$, and $y$ are defined as before. The $t$-statistics of the regression coefficients in the brackets are computed with corrections for heteroscedasticity and autocorrelation.

Surprisingly, we find little evidence that $\widehat{t a y}$ tracks $\widehat{c a y}$ for either the U.K. or Japan, in contrast to the finding by Brennan and Xia based on U.S. data. To be specific, the simple correlation between $\widehat{t a y}$ and $\widehat{c a y}$ is 0.34 for the U.K. and 0.16. for Japan. For our formal cross-sectional analysis, we investigate statistically whether $\widehat{t a y}$ may be a useful conditioning variable in helping explain the cross-sectional returns for either of the two countries. Our finding is summarized in Table 8.

\section{TABLE 8.}

Fama-MacBeth Regressions with TAY as the Conditional Variable

\begin{tabular}{|c|c|c|c|c|c|c|c|}
\hline CONT. & $E M R Q_{t}$ & $D R C O N_{t}$ & $D R I N C_{t}$ & $E M R Q_{t} * C A Y_{t-1}$ & $D R C O N_{t-1} * C A Y_{t-1}$ & $D R I N C_{t} * C A Y_{t-1}$ & $R^{2}$ \\
\hline \multicolumn{8}{|c|}{ Model 1: Consumption-based CAPM with TAY as the scaling variable } \\
\hline 3.05 & & 0.53 & & & -0.03 & & 0.16 \\
\hline $2.67(2.08)$ & & $1.54(1.11)$ & & & $-1.58(-1.27)$ & & 0.03 \\
\hline \multicolumn{8}{|c|}{ Model 2: Human Capital Augmented CAPM with TAY as the scaling variable } \\
\hline 7.52 & -5.01 & & 1.06 & -13.74 & & -0.19 & 0.24 \\
\hline $3.20(2.16)$ & $-2.06(-1.51)$ & & $0.85(0.68)$ & $-0.72(-0.54)$ & & $-0.07(-0.06)$ & -0.04 \\
\hline \multicolumn{8}{|c|}{ Panel B: Fama-MacBeth Cross-Sectional Regressions for Japan with TAY as the Scaling Variable } \\
\hline CONT. & $E M R Q_{t}$ & $D R C O N_{t}$ & $D R I N C_{t}$ & $E M R Q * C A Y_{t-1}$ & $D R C O N_{t} * C A Y_{t-1}$ & $D R I N C_{t} * C A Y_{t-1}$ & $R^{2}$ \\
\hline \multicolumn{8}{|c|}{ Model 1: Consumption-based CAPM with TAY as the scaling variable } \\
\hline-0.62 & & 1.19 & & & 0.47 & & 0.16 \\
\hline$-0.52(-0.33)$ & & $2.84(1.69)$ & & & $0.19(0.12)$ & & 0.08 \\
\hline \multicolumn{8}{|c|}{ Model 2: Human Capital Augmented CAPM with TAY as the scaling variable } \\
\hline-0.82 & 0.27 & & 2.16 & 2.20 & & -3.73 & 0.52 \\
\hline$-0.32(-0.20)$ & $0.10(0.06)$ & & $2.78(1.81)$ & $0.18(0.13)$ & & $-0.92(-0.61)$ & 0.42 \\
\hline
\end{tabular}

According to Table VIII, there is little evidence that $\widehat{\text { tay }}$ helps explain the cross-sectional returns for either country. Panel A of the table shows that, for the U.K., including $\widehat{\operatorname{tay}}$ as a scaling variable does not improve at all the ability of the CCAPM or the HC-CAPM in pricing the FamaFrench size and book-to-market equity double-sorted portfolio returns. On the contrary, when gauged by the adjusted $R^{2}$, the explanatory power of the two models even deteriorates in the presence of $\widehat{t a y}$ as a scaling variable, with the deterioration in the explaining power of the HC-CAPM be 
substantial as the adjusted $R^{2}$ drops from 0.02 to -0.04 . Similar deterioration in the explaining power of the CCAPM when $\widehat{t a y}$ is used as a scaling variable also holds for Japan. Though including tay as a scaling variable in the HC-CAPM helps somewhat in improving the model's ability in accounting for Japanese cross-sectional returns, such improvement is noticeably smaller than what is obtained when $\widehat{c a y}$ is used as a scaling variable instead. Overall, these cross-sectional regression results indicate that $\widehat{c a y}$ is unlikely to be a spurious variable. Its superior ability to $\widehat{t a y}$ in helping explain the cross-section of stock returns for the U.K. and Japan provides further evidence to support the theoretical implication that it may capture, at least in part, the time-varying information set concerning household investment-consumption behavior.

\section{CONCLUDING REMARKS}

This paper revisits an issue concerning the information content of the short-term deviations from long-run consumption-wealth relationship $(\widehat{c a y})$ in several popular asset-pricing models based on U.K. and Japanese data. We find that $\widehat{c a y}$ both helps forecast future stock returns and serves as a useful conditioning variable in a consumption-based capital asset-pricing model (CCAPM) and a human-capital-augmented capital asset pricing model (HC-CAPM) for explaining the cross-section of stock returns for the U.K. and Japan. Interestingly, in terms of relative performance, our results tend to favor the conditional HC-CAPM over the conditional CCAPM for pricing U.K. and Japanese cross-sectional returns. Our cross-sectional regressions using $\widehat{c a y}$ as a conditioning variable as opposed to using an alternative variable, $\widehat{\text { tay }}$, constructed using calender time in place of consumption indicate that it is unlikely to be a spurious variable and provides useful information concerning the economic fundamentals.

To check the robustness of our finding, we have also used the generalized method of moments in our empirical tests. The results are broadly consistent with those obtained using our baseline cross-sectional regression approach, although the coefficient estimates using the GMM are rather imprecise due to the well-known problem of the GMM associated with small sample properties of testing procedure and test statistics owing to the limited number of data points we have available for each country (see, also, Lettau and Ludvigson 2001b for the case with the U.S.). ${ }^{14}$

\footnotetext{
${ }^{14} \mathrm{~A}$ major issue in applying the GMM is the choice of the weighting matrix. In the literature, identity matrix, optimal weighting matrix, and the inverse of the second moment of the return matrix have all been used. Among others, Hansen, Heaton, and Yaron (1996) and Christiano and Den Hann (1996) argue that a second-stage GMM estimation is not suitable when the time-series sample relative to the cross-sectional sample is small. Cochrane (2001) offers a rule of thumb and recommends that if the
} 


\section{REFERENCES}

Ahn, Seung C., and Christopher Gadarowski, 2004, Small sample properties of the GMM specification test based on the Hansen-Jagannathan distance. Journal of Empirical Finance 11, 109-132.

Avramov, Doron, 2002, Stock return predictability and model uncertainty. Journal of Financial Economics 64, 423-458.

Basu, Sanjoy, 1977, Investment performance of common stocks in relation top their price earnings ratios: A test of market efficiency. Journal of Finance 32, 663-682.

Bertaut, Carol C., 2002, Equity prices, household wealth, and consumption growth in foreign industrial countries: Wealth effects in the 1990s, International Finance Discussion Papers 724, Board of Governors of the Federal Reserve System.

Breeden, Douglas T., 1979, An intertemporal asset pricing model with stochastic consumption and investment opportunities. Journal of Financial Economics 7, 265296.

Brennan, Michael J., and Yihong Xia, 2005, Tay's as good as cay. Finance Research Letters 1, 1-14.

Burnside, Craig, and Martin S. Eichenbaum, 1996, Small-sample properties of GMM based Wald tests. Journal of Business and Economic Statistics 14, 294-308.

Campbell, John Y., and John H. Cochrane, 1999, By Force of Habit: A consumptionbased explanation of aggregate stock market behavior. Journal of Political Economy 107, 205-251

Campbell, John, and Gregory Mankiw, 1989, Consumption, income, and interest rates: Reinterpreting the time series evidence. In NBER Macroeconomic Annual. Edited by Oliver Blanchard and Stanley Fischer. Cambridge: MIT Press.

Chan, Louis K. C., Yasushi Hamao, and Josef Lakonishok, 1991, Fundamentals and stock returns in Japan. Journal of Finance 46, 1739-1764.

Chordia, Tarun, and Lakshmanan Shivakumar, 2002, Momentum, business cycle, and time-varying expected returns. Journal of Finance 57, 985-1019.

Christiano, Lawrence J., and Wouter J. Den Haan, 1996, Small-sample properties of GMM for business-cycle analysis. Journal of Business and Economic Statistics 14, 309-37.

Cochrane, John H., 2001, Asset Pricing, Princeton University Press, Princeton, NJ.

Cochrane, John H., 1996, Production-based asset pricing and the link between stock returns and economic fluctuations. Journal of Finance 46, 209-237.

Daniel, Kent, Sheridan Titman and K.C. John Wei, 2001, Explaining the cross-section of stock returns in Japan: factor or characteristics? Journal of Finance, 743-766.

De Bont, Werner F.M., and Richard Thaler, 1985, Does the stock market overreact? Journal of Finance 40, 793-805.

cross-sectional sample size is less than one-tenth of the time-series sample size, then a first-stage GMM estimation shall be carried out as a robust check if a GMM procedure is used in the second stage. Given the relatively short time-series sample of our U.K. and Japanese data, both the optimal GMM weighting matrix of Hansen (1982) and the inverse of the second-moment of the return matrix of Hansen and Jagannathan (1997) are likely to be poorly estimated. Though using the inverse of the second moment of the return matrix may help to build Hansen-Jagannathan distance measure, recent simulation evidence by Ahn and Gadarowski (2004) illustrates the poor performance of test statistics associated with this particular weighting matrix. 
Dimson, Elroy, Stefan Nagel and Garrett Quigley, 2003, Capturing the value premium in the U.K. 1955-2001. Financial Analyst Journal 59, 35-45.

Fama, Eugene F., and Kenneth R. French, 1992, The cross-section of expected stock returns. Journal of Finance 47, 427-466.

Fama, Eugene F., and Kenneth R. French, 1993, Common risk factors in the returns on bonds and stocks. Journal of Financial Economics 33, 3-56.

Fama, Eugene F., and Kenneth R. French, 1996, Multifactor explanations of asset pricing anomalies. Journal of Finance 51, 55-84.

Fama, Eugene F., and Kenneth R. French, 1998, Value versus growth: The international evidence. Journal of Finance 53, 1975-1998.

Fama, Eugene F., and James D. MacBeth, 1973, Risk, return and Equilibrium: Empirical tests. Journal of Political Economy 81, 607-636.

Ferson, Wayne E., and Campbell R. Harvey, 1993, The risk and predictibility of international equity returns. Review of Financial Studies 6, 527-566.

Griffin, John M., 2002, Are the Fama and French factors global or country specific? Review of Financial Studies 15, 783-803.

Griffin, John, Susan Ji, and Spencer Martin, 2003, Momentum investing and business cycle risk: Evidence from pole to pole. Journal of Finance 58, 2515-2547.

Hansen, Lars Peter, 1982, Large sample properties of generalized method of moments estimators. Econometrica 50, 1029-1054.

Harvey, Campbell R., 1991, The world price of covariance risk. Journal of Finance 46, 111-157.

Hawawini, Gabriel, and Donald B. Keim, 2000, The cross section of common stock returns: a review of the evidence and some new findings, Security Market Imperfections in World-Wide Equity Markets. Edited by D. B. Keim and W. T. Ziemba. Cambridge University Press.

Hodrick, Robert J., and Xiaoyan Zhang, 2001, Evaluating the specification errors of asset pricing models. Journal of Financial Economics 62, 327-376.

Huang, Kevin X.D., and Zheng Liu, 2003, Multiple stages of processing and the quantity anomaly in international business cycle models, Working paper, Federal Reserve Bank of Kansas City and Emory University.

Jaffe, Jeffrey, Randolph Westerfield, and Donald B Keim, 1989, Earnings yields, market values and stock returns. Journal of Finance 44, 135-148.

Jagannathan, Ravi, and Zhenyu Wang, 1996, The conditional CAPM and the crosssection of expected returns. Journal of Finance 51, 3-53.

Jagannathan, Ravi, Kiichi Kubota and Hitoshi Takehara, 1998, Relationship between labor income risk and average return: Empirical evidence from the Japanese stock market. Journal of Business 71, 319-347.

Jagannathan, Ravi, Georgios Skoulakis, and Zhenyu Wang, 2003, Analysis of large cross sections of security returns. In Handbook of Financial Econometrics. Edited by Yacine Ait-Sahalia and Lars Peter Hansen.Elsevier Science Ltd.

Johansen, Soren, 1988, Statistical analysis of cointegrating vectors. Journal of Business and Economics Statistics 10,321-335.

Johansen, Soren, 1991, Estimation and hypothesis testing of cointegration vectors in Gaussian vector autoregressive models. Econometrica 56, 1551-1580.

Lakonishok, Josef, Andrei Shleifer, and Robert Vishny, 1994, Contrarian investment, extrapolation, and risk. Journal of Finance 49, 1541-1578. 
Lettau, Martin, and Sydney Ludvigson, 2001a, Consumption, aggregate wealth, and expected stock returns. Journal of Finance 56, 815-849.

Lettau, Martin, and Sydney Ludvigson, 2001b, Resurrecting (C)CAPM: A crosssectional test when risk premia are time-varying. Journal of Political Economy 109, 815-849.

Lettau, Martin, and Sydney Ludvigson, 2002, Tay's as good as cay: Reply, Working paper, Department of Economics, New York University.

Lettau, Martin, and Sydney Ludvigson, 2004, Understanding trend and cycle in asset values: Reevaluating the wealth effect on consumption. American Economic Review 94, 276-299.

Liew, Jimmy, and Maria Vassalou, 2000, Can book-to-market, size and momentum be risk factors that predict economic growth? Journal of Financial Economics 57, 221-245.

Lo, Andrew, and Craig MacKinlay, 1990, Data snooping biases in tests of financial asset pricing models. Review of Financial Studies 3, 431-468.

Newey, Whitey K., and Kenneth D. West, 1987, A simple positive semi-definite, heteroscedasticity and autocorrelation consistent covariance matrix. Econometrica 55, 703-708.

Phillips, Peter, and Sam Ouliaris, 1990, Asymptotic properties of residual based tests for cointegration. Econometrica 58, 165-193.

Rosenberg, Barr, Kenneth Reid, and Ronald Lanstein, 1985, Persuasive evidence of market inefficiency. Journal of Portfolio Management 11, 9-17.

Rudd, Jeremy, and Karl Whelan, 2002, A note on the cointegration of consumption, income and wealth, Working paper, Federal Reserve Board and Ireland Central Bank.

Shanken, Jay, 1992, On the estimation of beta-pricing models. Review of Financial Studies 5, 1-33.

Solnik, B., 1993, The unconditional performance of international asset allocation strategies using conditional information. Journal of Empirical Finance 1, 33-55.

Stock, James H., 1987, Asymptotic properties of least squares estimators of cointegrating vectors. Econometrica 55, 1035-1056.

Stock, James H., and Mark Watson, 1993, A simple estimator of cointegrating vectors in higher order integrated systems. Econometrica 61, 783-820.

Wang, Kevin Q., 2004, Conditioning information, out-of-sample validation, and the cross-section of stock returns. Working Paper, University of Toronto. 